\title{
Uma visão política-administrativa e morfológica dos balneários Esplanada e Campo Bom do Município de Jaguaruna, SC
}

\section{State of the political-administrative and morphological view of balneary Esplanada and Campo Bom in the Municipality of Jaguaruna, Santa Catarina}

\section{Cintia Becker 1, Eduardo Guimarães Barboza ${ }^{2}$ e Eduardo Marques Martins ${ }^{3}$}

1 Universidade Federal do Rio Grande do Sul, Instituto de Geociências, Geologia Marinha, Porto Alegre, Brasil. cintiabecker3@gmail.com. ORCID: https://orcid.org/0000-0001-7596-3547

2 Universidade Federal do Rio Grande do Sul, Centro de Estudos de Geologia Costeira e Oceânica, Coordenador do Laboratório de Sismoestratigrafia, Porto Alegre, Brasil. eduardo.barboza@ufrgs.br.

ORCID: https://orcid.org/0000-0003-2107-6904

3 Universidade Federal de Santa Catarina, Departamento de Ciências Naturais e Sociais, Centro de Ciências Rurais, Curitibanos, Brasil. geo.edum2@gmail.com.

ORCID: https://orcid.org/0000-0002-9185-3791

Recebido: 12/02/2019; Aceito: 28/07/2021; Publicado: 01/10/2021

Resumo: Historicamente, a urbanização litorânea se deu de forma desordenada e desplanejada causando grande pressão sobre os ambientes naturais. Com a finalidade de planejar o espaço e organizar os atores, surge a Gestão Costeira Integrada; alternativa que permite a avaliação e organização dos conflitos. O presente trabalho foi realizado na região centro-sul do Município de Jaguaruna/SC, nos balneários Esplanada e Campo Bom. Com o objetivo de entender o panorama do atual estado da região em relação ao Gerenciamento Costeiro Integrado, utilizou-se o Decálogo como ferramenta de identificação. Paralelamente, foi realizado um mapeamento do uso da terra, a fim de avaliar a ocupação urbana. Para entender o comportamento evolutivo da barreira costeira e identificar a origem dos corpos hídricos da região foram utilizados dados geofísicos obtidos com um Georadar (GPR). Os resultados mostraram que a expansão urbana ocorre em um litoral com padrão de empilhamento estratigráfico progradacional. Constatou-se, ainda, que a pouca eficácia e as dificuldades para a implementação de políticas e ações relacionadas à gestão costeira na esfera local decorrem de condições administrativas insuficientes, além da falta de recursos, tanto técnico quanto financeiros, para a implementação de projetos de melhoria das condições socioambientais da zona costeira.

Palavras-chave: Decálogo; Ocupação urbana; Georadar; GPR

\begin{abstract}
Historically, coastal urbanization happened in a disorderly and unplanned way, causing significant pressure on natural environments. In order to plan the space and organize the actors, Integrated Coastal Management emerges, an alternative that allows the assessment and organization of conflicts. This work was carried out in Esplanada and Campo Bom balnearies, region of Jaguaruna, municipality of Santa Catarina, Brazil. To understand the current state of Integrated Coastal Zone Management actions in the region, the "Decalogue" was used as an identification tool. At the same time, the land use was mapped to assess urban occupation. To know the local evolution of the coastal barrier and identify the origin of the water bodies in the region, geophysical data of Georadar (GPR) were used. The results showed that the urban expansion occurs on a coast with a progradational stratigraphic stacking pattern. It was also found that the lack of effectiveness and difficulties for the implementation of policies and actions related to coastal management at the local level are due to poor administrative conditions. In addition to the lack of resources, both technical and financial, to implement projects to improve the socio-environmental conditions of the coastal zone.
\end{abstract}

Keywords: Decalogue; Urban occupation; Ground-penetrating Radar; GPR 


\section{Introdução}

Segundo estimativas do Censo Populacional de 2010, 26,6\% da população brasileira mora em municípios da zona costeira, o equivalente a 50,7 milhões de habitantes; no entanto, a densidade populacional é heterogênea, variando entre locais sem ocupação e ambientes com mais de $5.000 \mathrm{hab} . / \mathrm{km}^{2}$. Visto que a zona costeira se caracteriza por uma grande diversidade de ambientes, com distintos usos da terra e conflitos socioambientais, é necessário um planejamento apropriado e esforços para mitigar os impactos provocados pela ocupação urbana (IBGE, 2011).

O Gerenciamento Costeiro Integrado (GCI) surgiu visando a compatibilização de conflitos, a fim de buscar um equilíbrio entre o desenvolvimento socioeconômico e a preservação ambiental. Dentre os objetivos do GCI destacamse a preservação e a proteção da produtividade e da biodiversidade dos ecossistemas, o reforço à gestão integrada por meio de medidas legais, capacitação e formação de pessoal e o desenvolvimento do uso racional e sustentável dos recursos marinhos (ASMUS et al., 2006).

O Município de Jaguaruna, devido à uma série de conflitos frequentes em Áreas de Preservação Permanentes (APPs), sofreu um embargo por parte do Ministério Público Federal (MPF) em 2011. Foram proibidas construções de infraestrutura de qualquer natureza em seus balneários costeiros. Na busca por alternativas, foi executado o projeto intitulado "Diagnóstico e Plano de Manejo das Dunas Frontais do Município de Jaguaruna", uma parceria entre a Universidade Federal do Rio Grande do Sul, o poder público municipal e a Associação dos Balneários de Jaguaruna (ABJ); com apoio da Universidade Federal de Santa Catarina (UFSC), de secretarias e órgãos estaduais, entre outros. O projeto teve como objetivos: (A) a realização de um diagnóstico da Orla Marítima e dos campos de dunas e ambientes adjacentes (área doravante denominada como "Dunas Interiores") e (B) a proposição de um plano de manejo baseado em cenários em escala municipal (1:10.000). o intuito do projeto era subsidiar estratégias de GCI na gestão municipal (GRUBER et al., 2017a).

O referido projeto gerou uma proposta de cenários de manejo baseados na dinâmica sedimentar costeira local, no mapeamento de conflitos e em instrumentos de gestão e planejamento preexistentes (GRUBER et al., 2017b). Tendo em vista a complexidade de informações geradas e a deficiência técnica dos gestores sobre GCI, bem como a falta de clareza sobre como e quem deveria aplicar a proposta de manejo desenvolvida, o presente trabalho avalia como as diversas instâncias de poder encaram e se posicionam em relação ao que se refere ao GCI nos balneários Esplanada e Campo Bom, Município de Jaguaruna.

Ademais, como a dinâmica costeira influencia a adoção e/ou a implementação de ações de GCI (BARBOZA et al., 2018), o presente trabalho apresenta uma avaliação sobre o padrão de empilhamento estratigráfico do sistema costeiro com o intuito de estimar se a área de estudo apresenta problemas relacionados à erosão costeira de longo período, conforme identificado em outros setores junto ao Cabo de Santa Marta (MARTINS et al., 2014; OLIVEIRA et al., 2019).

\section{Aspectos físicos da área de estudo}

A área de estudo abrange os balneários Esplanada e Campo Bom situados na região Centro-Sul do Município de Jaguaruna, limitados: ao Sudoeste, pelo balneário Torneiro; e ao Nordeste, pelo balneário Arroio Corrente (FIGURA 1). O contexto geológico está representado pelo setor costeiro da Bacia de Pelotas (DILLENBURG; BARBOZA, 2014). Conforme Fernandez et al. (2019), esse segmento costeiro do Litoral Sul de Santa Catarina é caracterizado morfologicamente por barreiras costeiras arenosas e lagunas formadas no Quaternário em condições de clima temperado. O modelo costeiro evolutivo da área de estudo é similar ao proposto por Villwock e Tomazelli (1995) para a zona costeira do Rio Grande do Sul, composto por quatro Sistemas Laguna-Barreira justapostos, oriundos de variações do nível relativo do mar (NRM) no Quaternário; contudo, na área de estudo não ocorrem registros dos Sistemas Laguna-Barreira I e II (pleistocênicos), encontrando-se somente os Sistemas Laguna-Barreira III e IV (pleistocênico e holocênico, respectivamente). Esses sistemas deposicionais são relacionados aos ciclos de sequências deposicionais de alta-frequência no registro estratigráfico (ROSA et al., 2011; 2017).

Em estudo realizado no balneário Campo Bom por Oliveira, Barboza e Benavente (2016) foi observado que a dinâmica local corresponde a de uma barreira arenosa holocênica do tipo progradacional, desenvolvida após o máximo eustático no Holoceno em torno de +2,5/+3,0 m acima no nível relativo do mar atual (ANGULO et al., 1999; BARBOZA et al., 2021a). Leal et al. (2016), através do Georadar e da análise de superfície por meio de técnicas de interpretação de fotografias aéreas e de imagens de satélite, constatou-se que a barreira costeira apresenta comportamento regressivo com influência do Rio Urussanga no balneário Torneiro, ao Sudoeste da área de estudo. 
De acordo com Horn Filho et al. (2012), a área de estudo abrange: depósitos eólicos e lagunares referentes ao Sistema Laguna-Barreira III, de idade pleistocênica; e depósitos eólico, lagunar, marinho praial, lagunar praial e flúvio-lagunar referentes ao Sistema Laguna-Barreira IV, de idade holocênica. De acordo com Gruber et al. (2017c), a granulometria e o perfil praial correspondem a um estágio morfodinâmico de praia dissipativa.

Conforme Alvares et al. (2013), a média anual de precipitação na região é de 1.300 e 1.600 mm, a temperatura anual permanece entre 18 e $2{ }^{\circ} \mathrm{C}$, e, de acordo com a classificação de Köppen, o clima da região é subtropical constantemente úmido (Cfa), sem estação seca e com verões quentes. Devido à presença do Anticiclone Tropical do Atlântico Sul, nos meses de primavera e de verão ocorrem predominantemente ventos dos quadrantes Leste e Nordeste; enquanto nos meses de outono e de inverno, devido ao Anticiclone Móvel Polar, os ventos predominantes são do quadrante Sul (ORSELLI, 1986).

A região possui um regime de micromaré semidiurno com variação média de 0,6 $\mathrm{m}$. Entretanto, sob influência de marés meteorológicas, a amplitude pode ser mais expressiva e atingir $1 \mathrm{~m}$ (GIANNINI, 1993). De acordo com Araújo et al. (2003), a altura de onda significativa é de 1,15 m (Leste) e 2,0 m (Sul), com períodos na faixa de 8 e $12 \mathrm{~s}$, respectivamente. Em uma escala regional, Siegle e Asp (2007) identificaram um caráter bidirecional da deriva litorânea, com predomínio para o sentido Sul - Norte nos meses de outono, inverno e verão, e para o sentido Sul na primavera. Porém, Oliveira, Barboza e Benavente (2016), em uma análise mais detalhada das correntes litorâneas na área de estudo, identificaram um predomínio da deriva no sentido Sudoeste.

A área de estudo também está sob influência da Área de Proteção Ambiental da Baleia Franca (APABF), a qual confere à região um nível de importância elevado para a conservação e preservação de áreas continentais e marinhas. Segundo Klein (1978), a área terrestre na qual está inserida a APABF é quase toda ocupada por vegetação litorânea, que se refere predominantemente a formações herbáceas e arbustivas, abrangendo agrupamentos e associações edáficos. Na área de estudo, especificamente, corresponde a um ambiente arenoso, com praia, dunas móveis e dunas fixas. Os benefícios proporcionados pelas dunas, além da estabilização da linha de costa, favorecem a diversidade de vegetação, constituindo-se um sistema único com condições ambientais diversas, onde se desenvolve uma vegetação e fauna características (FATMA, 2008). 


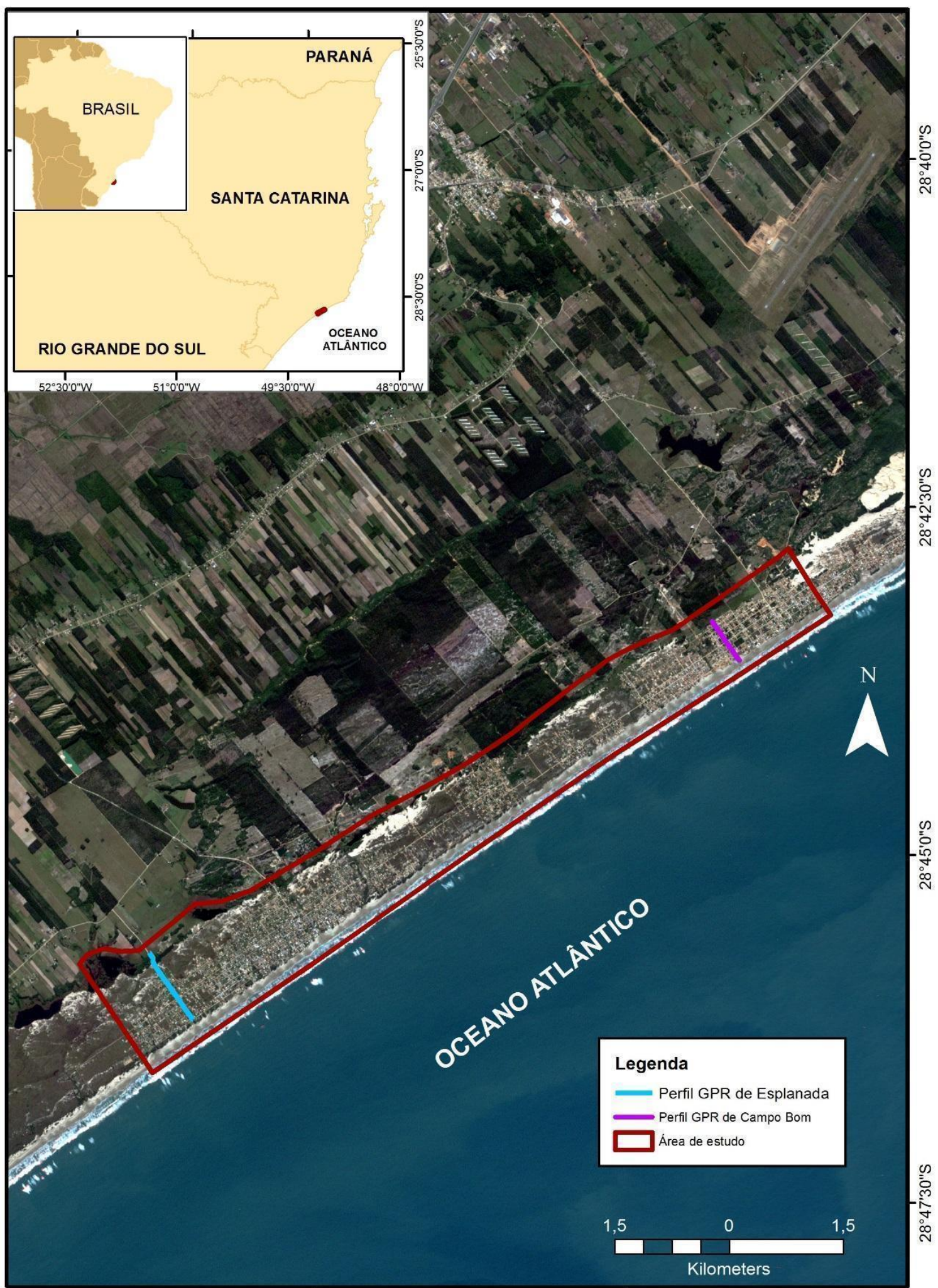

$49^{\circ} 7^{\prime} 30 \mathrm{WW}$

$49^{\circ} 5^{\prime} \mathrm{O}^{\mathrm{W}} \mathrm{W}$

FIGURA 1. Área de estudo: balneários Esplanada (ao Sudoeste) e Campo Bom (ao Nordeste) na região centro-sul do Município de Jaguaruna. Destacam-se os perfis de Georadar utilizados para a identificação do padrão de empilhamentos estratigráfico no local. Fonte: Google Earth, 28 de agosto de 2018. 


\section{Metodologia}

\subsection{Gestão Costeira Integrada}

A gestão costeira possui um conjunto de processos e formas de planejamento com objetivo de gerar condições para a utilização dos espaços e recursos naturais e culturais costeiros, de modo a promover sustentabilidade e viabilidade dos assentamentos humanos nestes ecossistemas (FERREIRA; ASMUS, 2019). Dentre os principais obstáculos que dificultam a real implementação da gestão costeira estão: a falta de apoio público; falta de acesso à informação; deficiência na planificação; escassez de recursos; falta de pessoal devidamente qualificado; desconhecimento de capacidades existentes; políticas de natureza setorial e não transversal (BARRAGÁN MUÑOZ, 2004; 2012).

Para a criação de um planejamento estratégico de gestão e aplicação de políticas públicas é necessário, primeiramente, conhecer os elementos estruturais do subsistema administrativo e jurídico da região que se pretende implementar a gestão costeira (BARRAGÁN MUÑOZ, 2012); permitindo, assim, valorar e comparar a situação do espaço geográfico costeiro com a finalidade de geri-lo de forma integrada.

A fim de elucidar o atual cenário da gestão da zona costeira da área estudada, bem como no âmbito estadual e federal, foi utilizado a metodologia proposta pela Red Iberoamericana de Manejo Costero Integrado (Red Ibermar) em 13 países Iberoamericanos de Barragán Muñoz (2010): o Decálogo, modelo de avaliação do estado de organização público-administrativo, a fim de apontar os entraves que dificultam a implementação de um projeto de GCI.

Os tópicos observados por essa metodologia são: 1) Políticas públicas - com o objetivo de identificar se o Estado possui políticas institucionais sobre GCI explícita e de conhecimento público; 2) Estrutura normativa - com o objetivo de averiguar se existem bases normativas que regulamentam a gestão de recursos e atividades costeiras; 3 ) Competências - com o objetivo de avaliar se existe em escala Nacional e Estadual distribuição de responsabilidade sobre a gestão integrada do espaço e os recursos marinhos; 4) Instituições públicas - com o objetivo de verificar se existe um marco institucional público que estabeleça as instituições mais envolvidas no assunto relacionados à gestão costeira; 5) Instrumentos estratégicos e operativos - com o objetivo de determinar se existem instrumentos estratégicos e operativos eficientes que orientem ações harmônicas entre instituições públicas e privadas para a GCI; 6) Formação e capacitação - com o objetivo de avaliar se existe um sistema apropriado para formar e capacitar gestores ligados à GCI; 7) Recursos econômicos - com o objetivo de determinar se existe uma congruência entre o nível de importância expressa pela administração pública e os recursos econômicos do orçamento público; 8) Conhecimento e informação - com o objetivo de saber se existe conhecimento sobre aspectos físicos e natural marinho, socioeconômico e cultural, e se essas informações estão disponíveis para cidadãos; 9) Educação para sustentabilidade - com o objetivo de avaliar se existe programas de educação ambiental nas escolas ou instituições não governamentais que realizam divulgação relacionada a costa e o meio marinho; 10) Participação cidadã - com o objetivo de saber se há grupos de cidadãos interessados em assuntos relacionados à GCI além do nível de engajamento destas instituições "não formais" na zona costeira (BÁRRAGAN MUÑOZ, 2012).

\subsection{Mapeamento de uso da terra}

De acordo com Casseti (1995), a Humanidade se apropria da natureza e a transforma, podendo fazer alterações relevantes na natureza, gerando modificação gradativa no potencial ecológico. Nesse contexto, para identificar as formas de apropriação do espaço na área de estudo, optou-se por usar dados do MapBiomas (MAPBIOMAS, 2019) disponíveis para a área de estudo. A partir da plataforma do MapBiomas foi possível exportar dados de uso da terra de 2018, desenvolvidos a partir de mosaicos de imagens do satélite de serviço LANDSAT-8.

Como os dados do MapBiomas são projetados para uso em escala regional (1:250.000), foram utilizadas imagens de alta resolução disponíveis nos softwares ArcGIS ${ }^{\circledR} 10.5$ e Google Earth Pro ${ }^{\circledR}$, mapeamento oriundo do projeto “Diagnóstico e Plano de Manejo das Dunas Frontais do Município de Jaguaruna" (GRUBER et al., 2018) e conhecimento de campo para refinar por interpretação visual o mapeamento do uso da terra. Com isso, optou-se por modificar a nomenclatura das classes, haja vista o detalhamento implementado: (i) Dunas Móveis e Vegetadas feição, com tamanho variado, que apresenta duas ou mais faces de deslizamento, formada pela ação do vento predominante sobre grãos de areia, os quais são soerguidos, transportados e depositados. As dunas são consideradas ativas ou móveis de acordo com a susceptibilidade de sofrer ação do vento: sendo geralmente fixas quando há 
presença de vegetação, que confere condições de maior umidade para a duna (HESP, 1988; 2000); (ii) Lençol de Areia Transgressivo - são depósitos de areia eólica formados pelo movimento de areia sobre terrenos vegetados ou semivegetados, cuja migração ocorre no sentido oceano - continente (HESP, 2000); (iii) Área urbana - área com média - alta ocupação urbana (residencial e/ou comercial); (iv) Corpo hídrico - denominação genérica para qualquer manancial hídrico, curso d'água, trecho de rio, reservatório artificial ou natural, lago, lagoa ou aquífero subterrâneo (ANA, 2014); (v) Curso d'água - conjunto de trechos de drenagem contínuos que, tomados a partir da foz, são reunidos no sentido jusante - montante (ANA, 2014); (vi) Silvicultura - cultivo de árvores para a produção de matériaprima variadas, sendo uma das atividades econômicas mais importantes para o Estado de Santa Catarina (RAMOS et al., 2006); (vii) Restinga Herbácea - vegetação com cerca de até 1 metro de altura, apresenta uma baixa diversidade de espécies (CONAMA, 1999); (viii) Restinga Arbustiva - vegetação constituída em sua maioria por plantas arbustivas com cerca de 1 a 5 metros de altura, as quais ocorrem em áreas bem drenadas ou paludosas (CONAMA, 1999); (ix) Praia - depósitos de sedimento, mais comumente arenosos, acumulados por ações de ondas, apresentando estado de alta mobilidade devido às condições de ondas e maré atuantes (MUEHE, 2018); (x) Dunas Frontais -sedimentos finos são carregados pela ação do vento até que encontrem obstáculos (geralmente plantas), os quais servem de substrato para o crescimento das dunas embrionárias. Pela combinação de alguns fatores (fonte de arenosa, grau de cobertura vegetal, taxa de acreção, erosão eólica etc.), as dunas embrionárias aumentam de volume e passam a se chamar dunas frontais (HESP, 2002).

Com o objetivo de avaliar a preservação de áreas com interesse ambiental na área de estudo, em ambiente de Sistemas de Informações Geográficas (SIG) foi realizada a sobreposição entre as classes de uso da terra, e as APPs e "Áreas de Proteção" (APs). As APs não têm caráter legal, mas foram sugeridas pela sua relevância à dinâmica ambiental pelo Comitê Gestor do Programa Estadual de Gerenciamento Costeiro de Santa Catarina (GERCO/SC) da Secretaria de Estado de Planejamento Regional de Santa Catarina (SPG/SC).

As proposições das (i) AP da Zona Costeira, faixa longitudinal continental de $300 \mathrm{~m}$ adjacente à linha de preamar, e $A P$ de Dunas, áreas com ocorrência de dunas móveis, foram um dos resultados de uma série de reuniões (2014 2015) com órgãos e instituições públicas (das três esferas de poder) e sociedade civil com atuação no Litoral CentroSul de Santa Catarina organizada pelo GERCO/SC. A adoção das APs neste trabalho, mesmo sem caráter legal, se deve a sua relevância ambiental e por serem um consenso construído entre representantes de públicos.

\subsection{Padrão de Empilhamento do Sistema Costeiro}

A compreensão do comportamento da barreira costeira é importante para a seleção de ações de GCI e a promoção de propostas de planejamento adequadas à dinâmica ambiental. Por essa razão, foi realizado um levantamento de georradar, normalmente empregado com a finalidade de identificar estruturas e feições geológicas que permitem identificar o estado evolutivo da barreira costeira, bem como possíveis estruturas remanescentes de períodos geológicos anteriores.

$\mathrm{Na}$ aquisição dos dados geofísicos, foi utilizado um sistema composto por um coletor Cobra Plug-In GPR (Radarteam Sweden $\mathrm{AB}$ ) juntamente com uma antena aérea SUBECHO SE-70 monoestática de frequência central de 80 $\mathrm{MHz}$, essa configuração permitiu uma janela de aquisição com tempo de ida e volta da onda (TWTT) de $650 \mathrm{ns,}$ equivalente a uma profundidade $30 \mathrm{~m}$. A constante dielétrica utilizada foi a de valor 10 para areia úmida que representa a velocidade de 0,09 m/ns (DAVIS; ANNAN, 1989) a qual foi utilizada para a conversão de tempo em profundidade. Essa constante foi validada em um sistema de cordões litorâneos regressivos (DILLENBURG et al.,

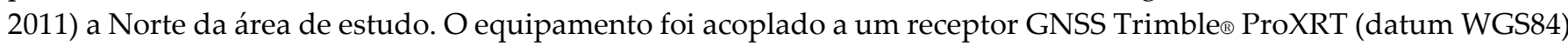
com intervalo de amostragem de $1 \mathrm{~s}$ com objetivo de correção topográfica. Durante a aquisição dos dados foram aplicados filtros de ruído e ganho.

No processamento realizado em laboratório, com intuito de eliminar os ruídos do perfil obtido e melhoria na qualidade, os dados obtidos foram convertidos do formato SGY para o formato DZT no software Reflex-Win ${ }^{\circledR}$ (Sandmeier Geophysical Research). Após os dados foram processados com os filtros de background removal e a aplicação de filtros de frequência passa banda no software RADAN ${ }^{T M}$ (Geophysical Survey Systems, Inc.), e por fim no software Prism ${ }^{\circledR} 2.5$ (Radar Systems, Inc.) foram aplicados o filtro Ormsby bandpass, a equalização de ganho, a conversão de tempo para profundidade, o ajuste do tempo zero e a correção topográfica com os dados altimétricos obtidos com o sistema GNSS. A análise de traço do sinal, conforme Leandro et al. (2019), auxiliou na determinação do contato entre os depósitos dos ambientes deposicionais. A interpretação dos dados seguiu o método 
sismoestratigráfico com base nas terminações, geometria e padrão de refletores (MITCHUM Jr.; VAIL; SANGREE, 1977) adaptado para o Georadar por Neal (2004). Esse método é baseado na terminação de refletores, geometria e padrão de empilhamento dos refletores (ABREU; NEAL; VAIL, 2010). A interpretação do padrão de empilhamento estratigráfico, considerando outros setores similares na Bacia de Pelotas, foi baseado nos estudos de Barboza et al. (2011, 2014, 2018, 2021b) e de Bitencourt et al. (2020). Não foi executada a migração dos dados devido ao objetivo do estudo ser a análise do padrão de empilhamento estratigráfico das reflexões da unidade deposicional holocênica.

\section{Resultados}

\subsection{Gestão Costeira Integrada}

Conforme informações levantadas sobre a gestão costeira do litoral de Santa Catarina e analisando especialmente o que se refere ao Município de Jaguaruna, os quatro primeiros princípios do Decálogo foram reunidos em dois grupos: Políticas Públicas e Estruturas Normativas; Competências e Instituições Públicas; os demais princípios foram apresentados individualmente.

\subsubsection{Políticas Públicas e Estruturas Normativas}

O Estado de Santa Catarina segue as diretrizes do Plano Nacional de Gerenciamento Costeiro (PNGC II), estabelecido pela Resolução CIRM n 05/1997, através do Programa Estadual de Gerenciamento Costeiro de Santa Catarina (GERCO/SC) referente ao que foi proposto pelo Plano Estadual de Gerenciamento Costeiro (PEGC) (ANDRADE; SCHERER, 2014). Conforme o Plano de Gestão da Zona Costeira do Setor 4 (PGZC-S4) (Decreto Estadual $n^{\circ}$ 5.010/2006), do qual faz parte o Município de Jaguaruna, os municípios foram estimulados a analisar, discutir e compatibilizar o zoneamento realizado pelo GERCO/SC com o zoneamento de cada plano diretor municipal, com o objetivo de criar ações de zoneamento e plano de gestão (GERCO/SC, 2010; SPG, 2010a).

Conforme o Plano Diretor Municipal de Jaguaruna (PDM), instituído pela Lei Complementar $\mathrm{n}^{\circ}$ 04/2014, o Município passa a ter sua gestão territorial definida por meio do: (i) Macrozoneamento, o qual corresponde a divisão territorial, com o intuito de definir para cada um dos espaços o seu interesse e finalidade específica. Dentre as macrozonas estabelecidas, temos a Macrozona do Ambiente Natural, que compreende áreas de preservação ambiental; (ii) Zoneamento, que visa gerar para cada região a utilização mais adequada de acordo com as determinações do macrozoneamento.

Dentre os objetivos das normas gerais da política ambiental de Jaguaruna, baseada na Política Nacional e Estadual do Meio Ambiente e integrada ao Sistema Nacional do Meio Ambiente (SISNAMA), consta o fomento e o desenvolvimento sustentável alicerçado na justiça social, crescimento econômico e no equilíbrio ambiental (JAGUARUNA, 2014).

\subsubsection{Competências e Instituições Públicas}

Conforme o Plano Nacional de Gerenciamento Costeiro, instituído pela Lei Federal n ${ }^{\circ} .661 / 1988$, a gestão costeira deve ser exercida nos seguintes níveis de poder: União, Estados, Territórios e Municípios, por meio de órgãos e entidades integradas ao SISNAMA. Segundo Art. $6^{\circ}$ da Lei Estadual $n^{\circ} 13.553 / 2005$, que define o Plano Estadual de Gerenciamento Costeiro e Santa Catarina, deve ser organizado através da Secretaria Estadual de Desenvolvimento Sustentável de Santa Catarina (SDS) com colaboração da Secretaria de Estado de Desenvolvimento Regional, municípios costeiros, sociedade civil organizada e iniciativa privada. Contudo, desde 2008, com a aprovação da Lei Estadual n ${ }^{\circ} 14.465 / 2008$, o órgão responsável pela implementação do Programa Estadual de Gerenciamento Costeiro (GERCO/SC) vem sendo a Secretaria de Estado do Planejamento (SPG), órgão não vinculado a SISNAMA. O Conselho Estadual de Meio Ambiente (CONSEMA) apresenta uma Câmara Técnica do Gerenciamento Costeiro (CTGERCO), cuja finalidade é avaliar as ações do GERCO/SC. O CONSEMA e CTGERCO têm participação de diversos órgãos ambientais, sociedade civil organizada e universidades (ANDRADE; SCHERER, 2014).

O Instituto do Meio Ambiente de Jaguaruna (IMAJ) é uma autarquia de personalidade jurídica de direito público, cujas normas são estabelecidas pela Lei Municipal n 1.413/2011, a qual segue os pressupostos legais instituídos nas esferas municipal, estadual e federal (JAGUARUNA, 2011). O IMAJ tem várias finalidades, entre elas: implantar, 

naturais; o controle dos padrões de qualidade ambiental; análise e aprovação dos pedidos de licença ambiental.

\subsubsection{Instrumentos e Estratégias}

O Plano de Ação Federal para a Zona Costeira (PAF-ZC), instituído pela Lei Federal n 7.661/1988 e regulamentado pelo Decreto Federal n ${ }^{\circ}$ 5.300/2004, visa o planejamento de ações relacionadas à gestão costeira, priorizando ações que desenvolvam a capacitação de pessoas e instituições de políticas públicas (MMA, 2017).

De acordo com o PNGC II, todos os estados e municípios devem replicar os instrumentos brasileiros de gestão costeira. Os instrumentos que permitem a implantação do Plano Estadual de Gerenciamento Costeiro são: o Zoneamento Ecológico Econômico Costeiro (ZEEC); o Plano de Gestão da Zona Costeira (PGZC); o Sistema de Informações do Gerenciamento Costeiro (SIGERCO); o Sistema de Monitoramento Ambiental (SMA/ ZC); o Relatório de Qualidade Ambiental (RQA/ZC) e o Projeto de Gestão Integrada da Orla Marinha (Projeto Orla) (Santa Catarina, 2005). Contudo, esses instrumentos estão nas seguintes fases de desenvolvimento (SPG, 2010b): i) não desenvolvido/implantado, SIGERCO, SMA/ZC e RQA/ZC; ii) em desenvolvimento, PEGC, ZEEC, PGZC e Projeto Orla.

O Plano de Manejo da APABF, UC que abrange parcialmente o Município de Jaguaruna, foi elaborado por meio de uma metodologia participativa inovadora, visando focar mais na orientação de um planejamento estratégico do que em normativas, integrando as demais esferas de governo na medida em que orienta um conjunto de ações da sociedade, com base em pactos sociais (MMA, 2018). No entanto, uma decisão liminar proferida em 25 de julho de 2019 atende um pedido feito em recurso ajuizado por associações comerciais e empresariais de diversos municípios do litoral catarinense, incluindo a Associação Empresarial de Jaguaruna e de Sangão (ACIRJ), e suspende a aplicação do Plano de Manejo da APABF.

O Município de Jaguaruna conta, ainda, com a proposta de plano de manejo da Orla Marítima e das Dunas Interiores oriundo do projeto "Diagnóstico e Plano de Manejo das Dunas Frontais do Município de Jaguaruna", o qual caracteriza e avalia os impactos ao meio ambiente costeiro local e serve de fonte de informações para o planejamento e gestão pública local.

\subsubsection{Formação e Capacitação}

Das instituições que possuem cursos no Ensino Superior e/ou Técnico voltados à zona costeira, o estado de Santa Catarina possui duas instituições de ensino federais (Instituto Federal de Educação, Ciência e Tecnologia - IFSC - e a Universidade Federal de Santa Catarina - UFSC). Em nível estadual conta com Universidade do Estado de Santa Catarina (UDESC) e a Universidade do Vale do Itajaí (UNIVALI). Segundo Andrade e Scherer (2014), em Santa Catarina ainda não existem cursos que tenham como foco a capacitação e/ou formação de gestores e administradores públicos com vistas à Gestão Costeira Integrada.

\subsubsection{Recursos Econômicos}

O Plano de Gestão da Zona Costeira do Setor 4 (SPG, 2013), no qual se insere o Município de Jaguaruna, define que os recursos econômicos para os programas e projetos de gestão na zona costeira são de diversas fontes, incluindo iniciativas privadas. O referido documento, o Município de Jaguaruna para usufruir de uma gestão dos recursos naturais necessita de recursos do Fundo dos Bens Lesados do Ministério Público Estadual e Federal, outros Fundos estaduais, Fundo Nacional do Meio Ambiente e recursos dos municípios.

A proposta de plano de manejo da Orla Marítima e Dunas Interiores de Jaguaruna foi realizado a partir do fomento financeiro promovido pelo Estado de Santa Catarina e parceria com a Associação dos Balneário de Jaguaruna (ABJ) (IDALÊNCIO; PACHECO, 2019). No entanto, apesar de ser uma área de extrema importância econômica e ambiental para o Município, não existe um fundo específico destinado às ações (atuais e futuras) de gestão costeira. Além disso, a disponibilidade de recursos humanos, técnicos e tecnológicos para implementar a gestão costeira no Município de Jaguaruna é limitada. 


\subsubsection{Conhecimento e Informação}

A UFSC, a UDESC e a UNIVALI são instituições de Ensino Superior em Santa Catarina que ofertam vagas para cursos de graduação e pós-graduação que têm se voltado à zona costeira, tais como: Oceanografia, Geologia, Geografia, Ciências Biológicas, entre outros. A UFRGS, a Universidade Federal do Rio Grande (FURG) e a Universidade de São Paulo (USP) também são referências na formação (Graduação e Pós-graduação) de profissionais com especialidades voltadas à zona costeira.

Apesar de existir produção de conhecimento relevante voltado à zona costeira, o conteúdo é produzido de forma esparsa, e o conhecimento gerado não se encontra sistematizado, organizado (SPG, 2010a); o que prejudica o desenvolvimento de diagnósticos socioeconômicos do litoral. Mesmo que a falta de conhecimento dos ambientes costeiros ainda é mais marcante na região Sul de Santa Catarina (ANDRADE; SCHERER,2014), na área de estudo podem-se citar os trabalhos de Giannini (1993; 2002), de Giannini e Santos (1994), de Martinho (2004), de Horn Filho (2012) e do próprio Plano Diretor Municipal de Jaguaruna (JAGUARUNA, 2014) como fontes de informação sobre a região e a área de estudo.

O projeto “Diagnóstico e Plano de Manejo das Dunas Frontais do Município de Jaguaruna”, que resultou em uma proposta de plano de manejo da Orla Marítima e Dunas Interiores de Jaguaruna, gerou um grande volume de informações, referentes aos diversos tipos de ambiente encontrados no Município. Os relatórios produzidos foram entregues a Câmara de Vereadores em fevereiro de 2019 com o intuito de subsidiar a tomada de decisões e ações ligadas ao GCI no Município de Jaguaruna (IDALÊNCIO; PACHECO, 2019).

\subsubsection{Educação para Sustentabilidade}

O Programa Estadual de Educação Ambiental (ProEEA/SC), regulamentado pelo Decreto Estadual n³.726/2010, visa estabelecer um conjunto de ações estratégicas, critérios e metodologias em Educação Ambiental integradas aos programas de conservação, recuperação e uso sustentável do meio ambiente. Santa Catarina também conta com o "Portal de Educação Ambiental", mantido pela Comissão Interinstitucional de Educação Ambiental (CIEA), cuja finalidade é "disponibilizar livremente material e conteúdo de projetos, estudos, atividades ou trabalhos realizados na educação ambiental". Esse Portal foi desenvolvido por uma equipe multidisciplinar da UNIVALI, financiada pela Fundação de Amparo à Pesquisa e Inovação do Estado de Santa Catarina (FAPESC) (EDUCAÇÃO AMBIENTAL, 2014).

O "Projeto Golfinho" promovido pelo Corpo de Bombeiros Militar de Santa Catarina durante a “Operação Veraneio" tem como finalidade ensinar o público infantil sobre os riscos associado ao banho de mar, além de promover atitudes de respeito e convívio equilibrado com o meio ambiente (CAMILO, 2019). A Legião da Boa Vontade (LBV) também desenvolve ações voltadas para educação ambiental, tais como: conscientização sobre o desperdício de água e separação do lixo reciclável, bem como a necessidade de preservar os recursos naturais, entre outros (NETTO, 2019).

\subsubsection{Participação cidadã}

No Município algumas associações da sociedade civil apresentam interesse em assuntos ligados à zona costeira e gestão costeira: a Associação dos Balneários de Jaguaruna (ABJ), que firmou parceria e apoiou o desenvolvimento do projeto “Diagnóstico e Plano de Manejo das Dunas Frontais do Município de Jaguaruna”, e associações de pescadores artesanais são exemplos disso.

Por outro lado, a CIRJ fiz parte do grupo que ingressou com uma ação civil pública que suspendeu a execução do Plano de Manejo da APABF. As associações alegaram que parte das áreas zoneadas já estão protegidas por lei, o que tornaria ilegal e desnecessária uma nova limitação administrativa. Além de afirmarem que o plano traz prejuízo às políticas públicas de ordenamento e regulamentação das áreas territoriais dos municípios abrangidos pela UC (TRF4, 2019). 


\subsection{Mapeamento de uso da terra}

A partir dos dados levantados e adaptados do projeto MapBiomas foi possível gerar o mapa de uso da terra da área de estudo (FIGURA 2), onde é possível observar áreas residenciais densamente ocupadas, interconectadas, em sua maioria, por vias não pavimentadas (chão batido). Essas zonas urbanas são compostas por edificações de um ou dois pavimentos, com predomínio de "segunda residência" (residências ocupadas de forma sazonal, principalmente no verão), e estabelecimentos comerciais e de serviços (local). Segundo Gruber et al. (2018), em 2012 a região apresentava duas manchas urbanas homogêneas, referentes aos balneários Esplanada e Campo Bom; no entanto, é provável que se tornem uma área urbanizada contínua nos próximos anos.

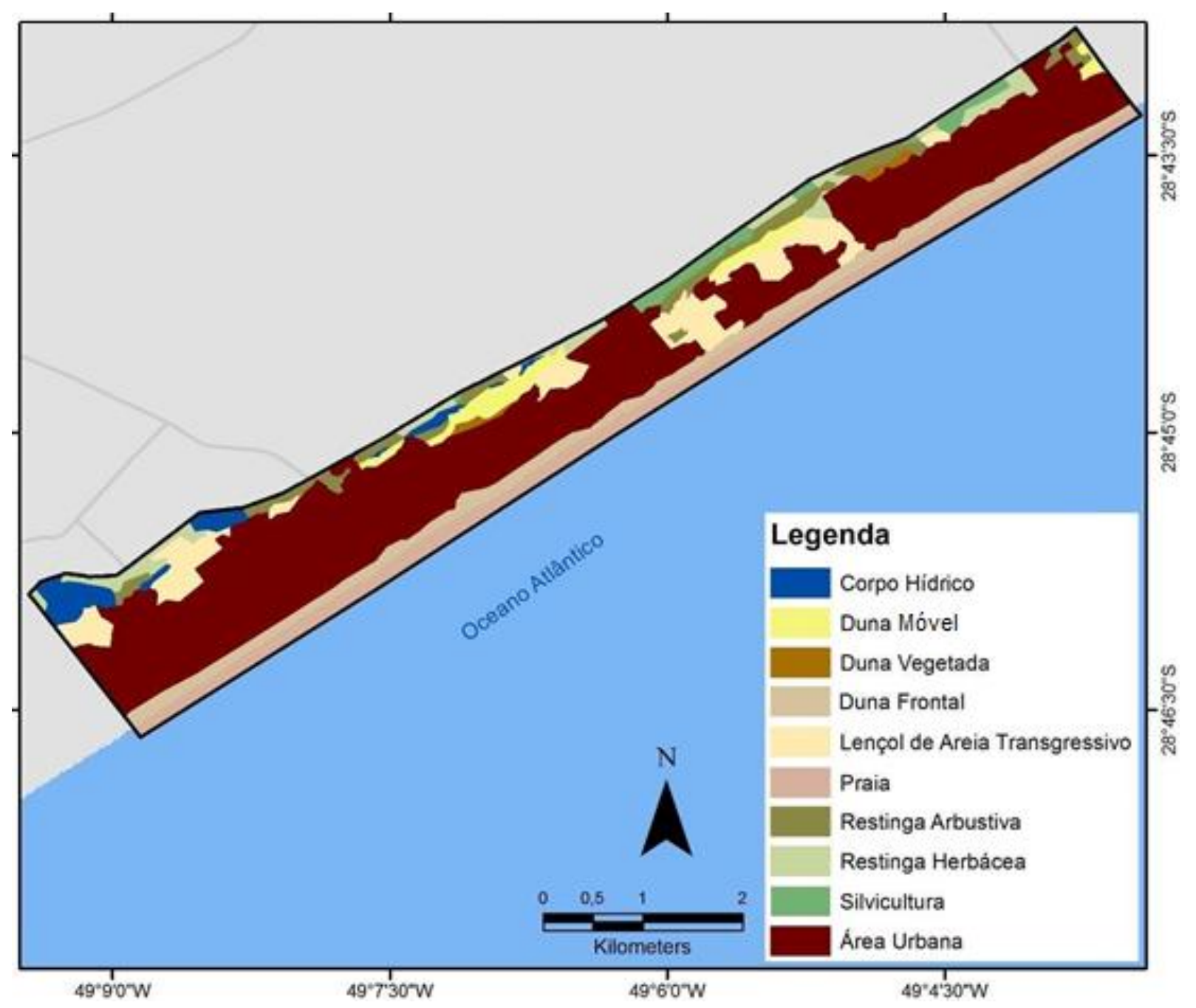

FIGURA 2: Mapa elaborado neste estudo evidenciando o uso da terra na área pela área urbanizada.

Por meio de imagens orbitais de alta resolução do Google Earth Pro ${ }^{\circledR}$, entre os anos de 2008 e 2018 , foi possível observar o adensamento de áreas urbanas consolidadas e o surgimento de zonas de ocupação incipiente; as quais, devido a sua expansão recente, tendem a se conectar às manchas urbana adjacentes (FIGURA 3). O Balneário Esplanada é constituído por residências que apresentam melhores condições infraestruturais: acabamento e condições de habitação, algumas delas localizadas no reverso da duna frontal. 

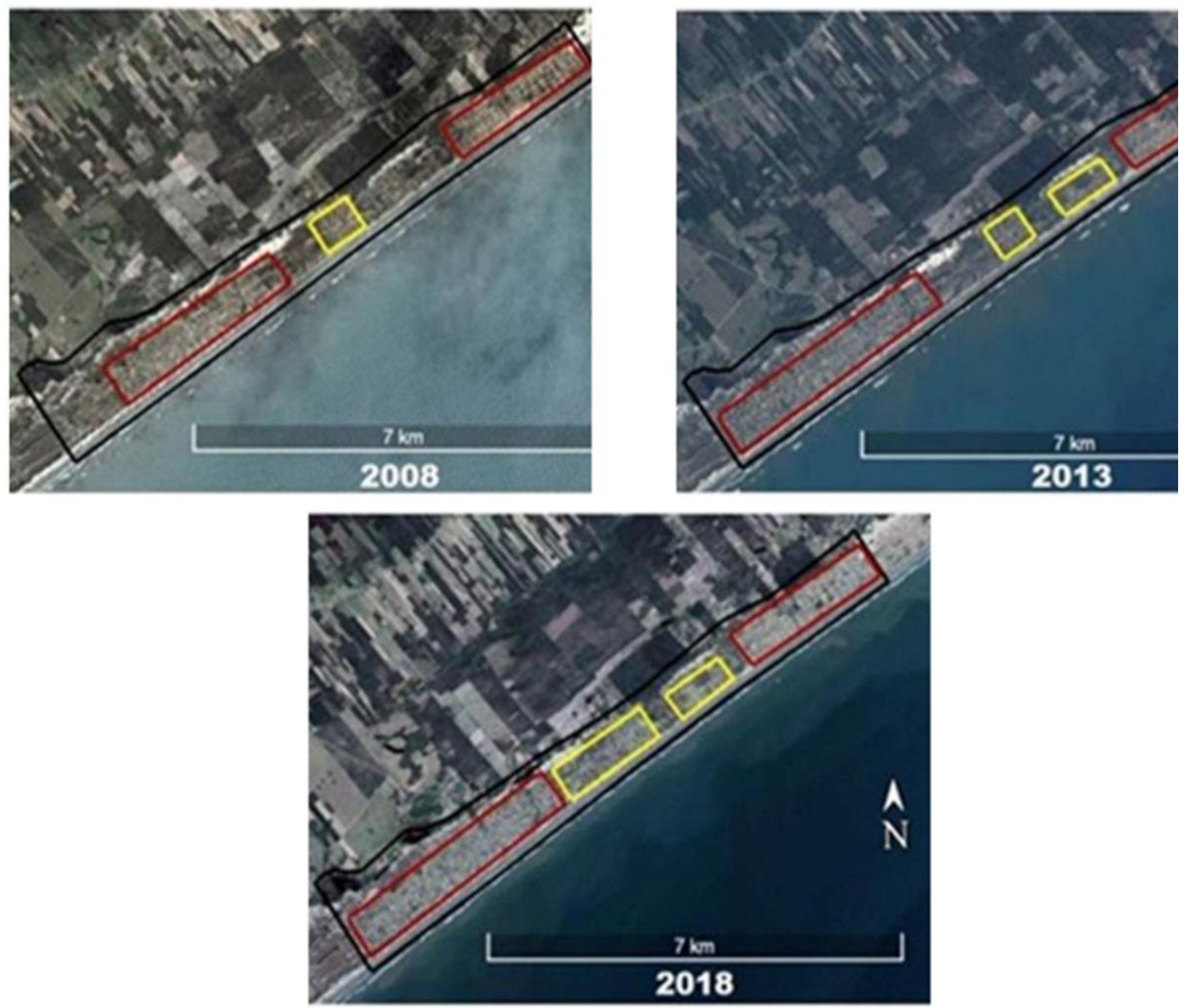

FIGURA 3. Ocupação na área de estudo nos anos de 2008, 2013 e 2018. Destacam-se duas áreas densamente ocupadas (retângulos vermelhos) e uma área de ocupação incipiente em expansão (retângulos amarelos).

A partir do mapeamento de lençóis de areia com cristas de precipitação no Balneário Torneiro (LEAL; BARBOZA; BENAVENTE, 2016) (ao Sudoeste da área de estudo). Também são observados no Balneário Esplanada lençóis de areias transgressivos, essa unidade ocorre em contato com a área urbanizada e próximo das dunas vegetadas (FIGURA 4). Normalmente, são superfícies onduladas, com desnível topográfico limitado e com lençol freático raso (é comum observar feições que sinalizam canais efêmeros e encharcamentos periódicos). 


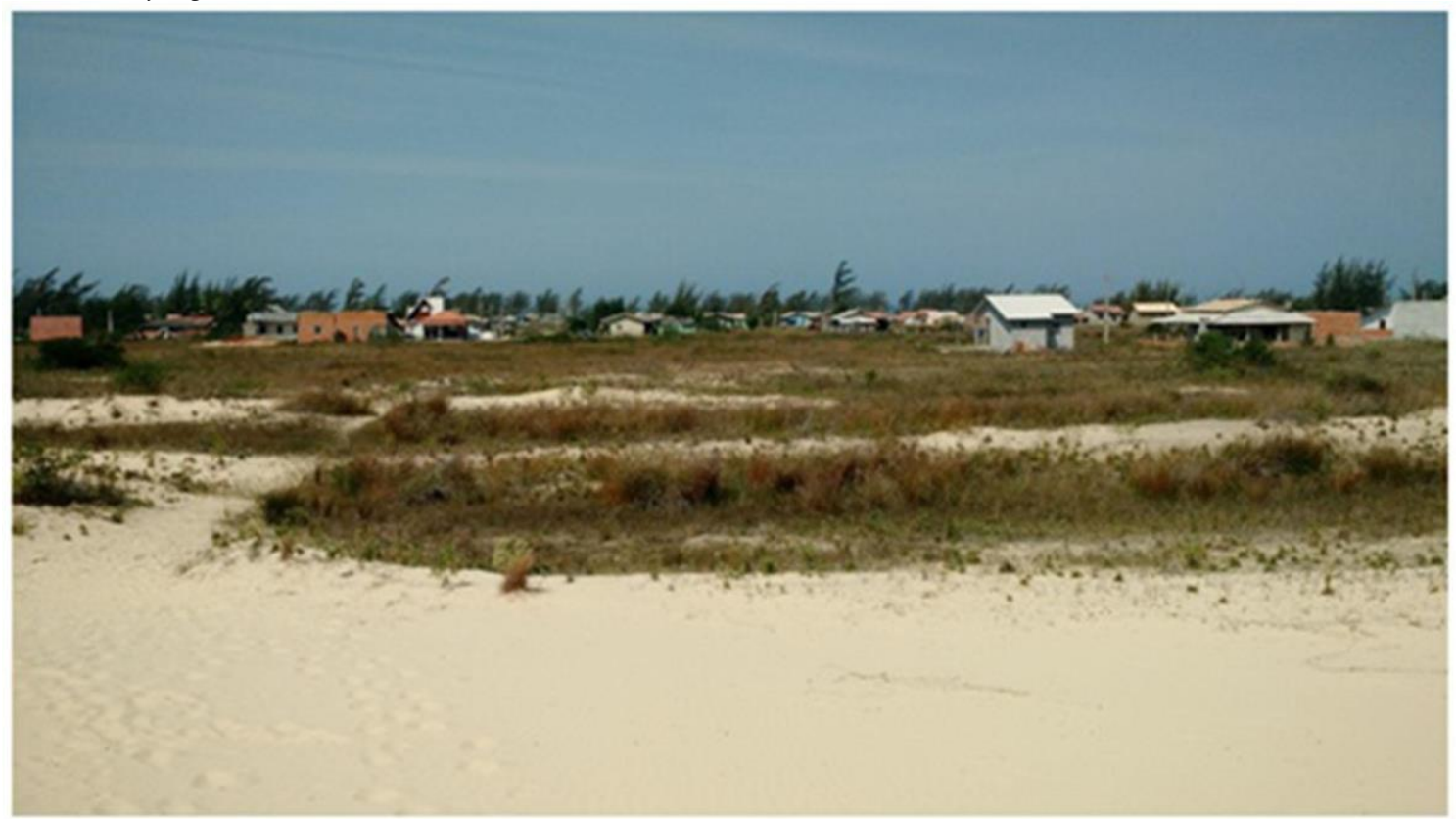

FIGURA 4. Lençol de areia identificado no Balneário Esplanada. Em primeiro plano, o contato com o campo de dunas móveis e região ocupada pela área urbanizada. Fonte: Gruber et al. (2018).

Os campos de dunas móveis na área de estudo são de pequena proporção, ocorrendo nas regiões com uma menor densidade urbana. As dunas frontais são bem desenvolvidas no Balneário Esplanada, se comparadas com as ocorrências no Balneário Campo Bom. Em ambos os balneários ocorre a presença da vegetação exótica (Casuarina spp.) nas proximidades das dunas frontais (FIGURA 5).
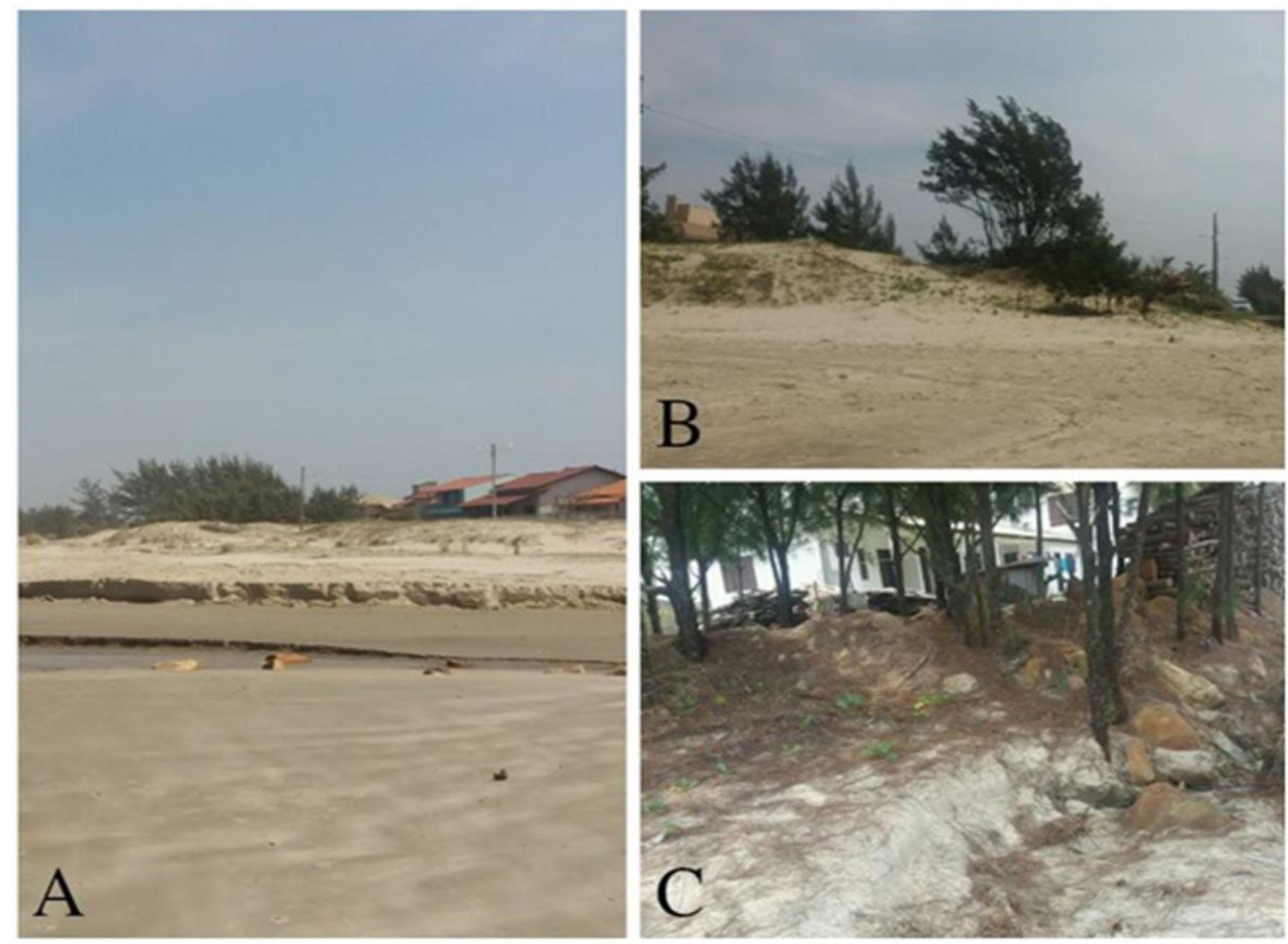

FIGURA 5. Vista das dunas frontais nos balneários Campo Bom (A) e Esplanada (B). Presença de residência de dois pavimentos no reverso da duna frontal no Balneário Esplanada (C). Fonte das fotografias: autores. 
As restingas arbustiva e herbácea encontram-se presentes próximas aos corpos d'água, banhados e áreas úmidas. A restinga herbácea é relevante no processo de pedogênese e na fixação dos sedimentos dos lençóis de areia. A silvicultura refere-se ao plantio de Pinus spp. e/ou Eucaliptus ssp. nas regiões adjacentes a zona urbanizada (FIGURA 5).

Para uma correlação mais clara do estado atual da conservação das áreas de APPs em relação às áreas urbanas, foram sobrepostas informações geradas pelo mapeamento de uso da terra com o mapeamento das áreas com restrição legal. Apesar de que foi possível observar que parte da zona urbanizada invade as áreas de APP, na grande maioria das vezes, as manchas urbanas dos balneários Esplanada e Campo Bom se mantêm no limite das APPs. A AP da Zona Costeira é ocupada ao longo de toda a sua ocorrência em ambos os balneários, com algumas exceções na área de ocupação urbana incipiente (FIGURA 6).

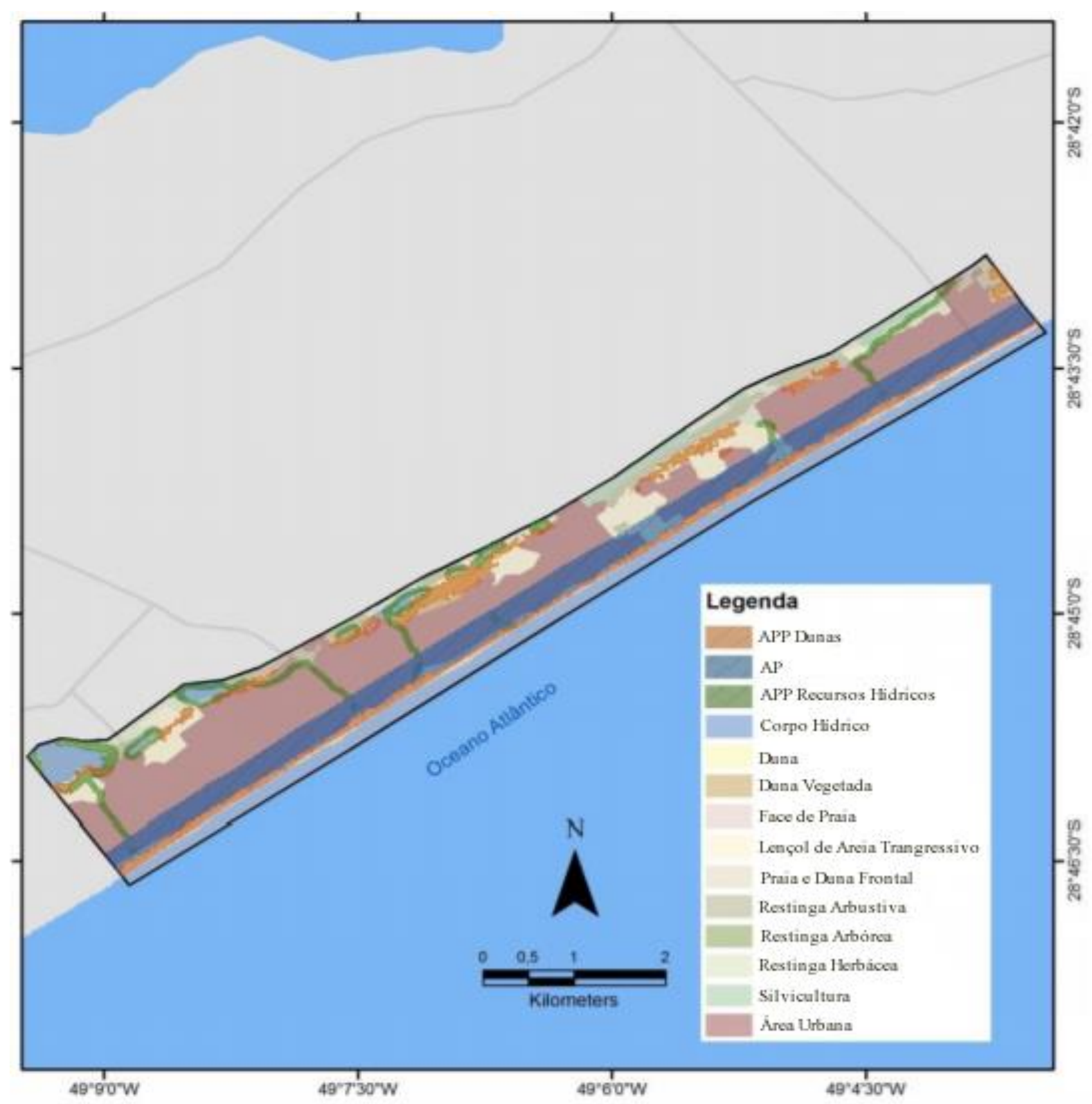

FIGURA 6. Áreas de Preservação Permanente (APP) e Áreas de Proteção (AP) sobrepostas ao mapeamento de uso da terra. 


\subsection{Padrão de Empilhamento do Sistema Costeiro}

A partir da interpretação dos registros de Georadar (FIGURAS 7 e 8) foram definidas quatro distintas unidades deposicionais e/ou ambientes: I - depósitos correspondentes ao substrato pleistocênico; II - depósitos correspondentes ao perfil praial (emerso e submerso); III - depósitos fluviais; IV - depósitos eólicos.

Os depósitos correspondentes ao substrato pleistocênico (I) possuem reflexões com alta amplitude do sinal com a presença de hipérboles de difração, aos quais são características de paleosolos (BITENCOURT et al., 2020). Os depósitos relacionados ao sistema praial possuem reflexões com alta amplitude do sinal com inclinação no sentido do oceano, são essencialmente contínuas e por vezes onduladas, com mergulho sobre uma superfície com alta amplitude ou sobre hipérboles conforme interpretado por Barboza et al. (2011, 2013) e por Oliveira et al. (2019) em outros setores da Bacia de Pelotas. Essa unidade é caracterizada pela presença das zonas de pós-praia, de estirâncio, de surfe, e de antepraia. A unidade correspondente aos depósitos fluviais (III) é observada somente na seção do Balneário Esplanada, é delimitada na base por superfícies côncavas com padrão de preenchimento interno composto por formas sigmoidais com sentido de migração para o continente. Essas formas sigmoidais estão associadas ao preenchimento de canais por barras de margem de canal, conforme descritas por Barboza et al. $(2014,2021 b)$ na região da Praia da Pinheira/SC e do banhado do Taim/RS, respectivamente, e por Biancini da Silva (2014) na região de Passo de Torres/SC. Os depósitos da unidade IV correspondem à cobertura eólica, cujas reflexões caracterizam-se por alta amplitude, serem contínuas e onduladas com baixo ângulo, e ocorrem no topo dos registros, conforme observado por Barboza et al. (2013) na região de Curumim/RS e por Dillenburg et al. (2017) na região do Cassino/RS.
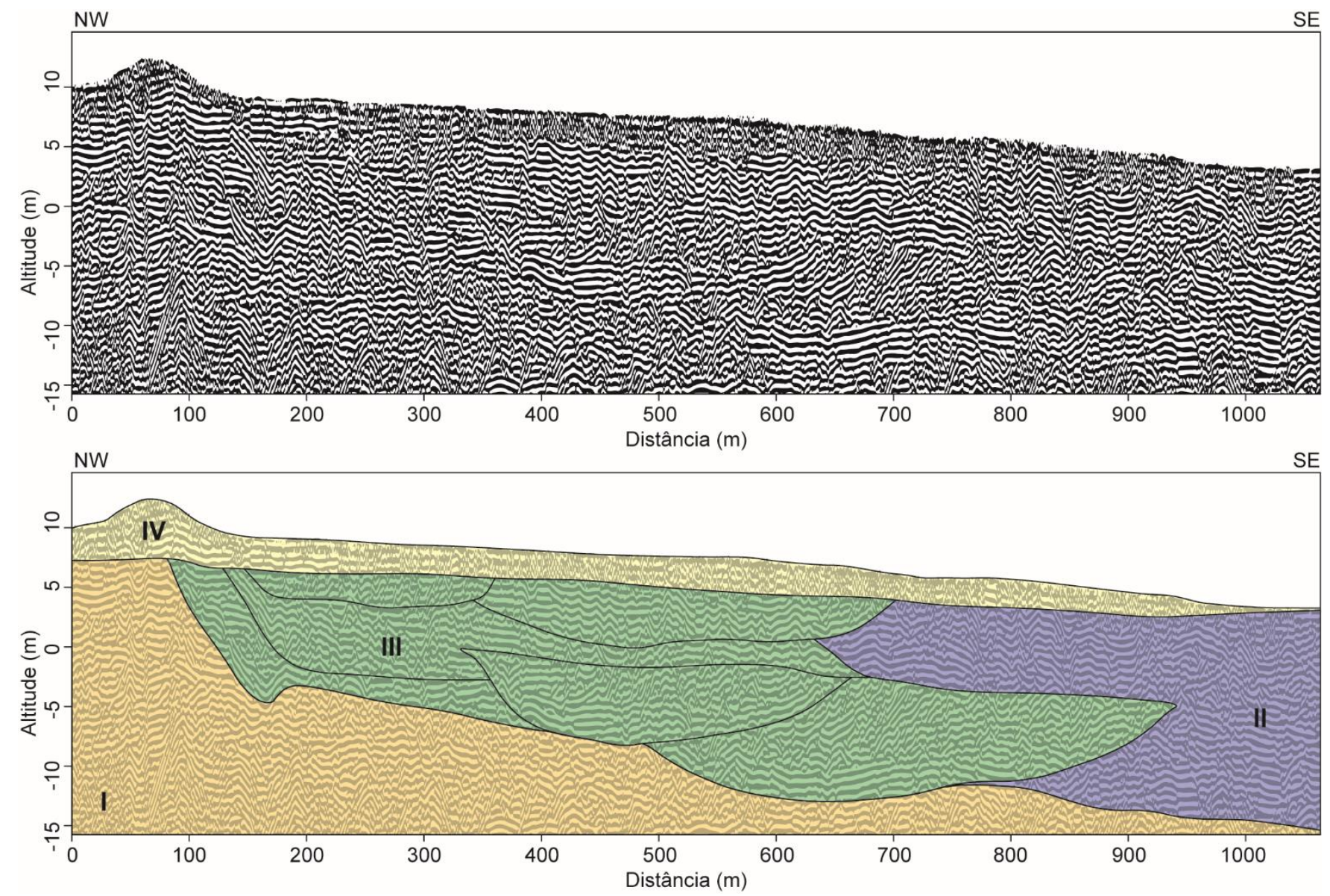

FIGURA 7. Imagem acima apresentando o radargrama processado do Balneário Esplanada. Abaixo o registro estratigráfico interpretado com as respectivas unidades deposicionais e/ou ambientes: I - depósitos correspondentes ao substrato pleistocênico; II - depósitos correspondentes ao perfil praial (emerso e submerso); III - depósitos fluviais; IV - depósitos eólicos. 

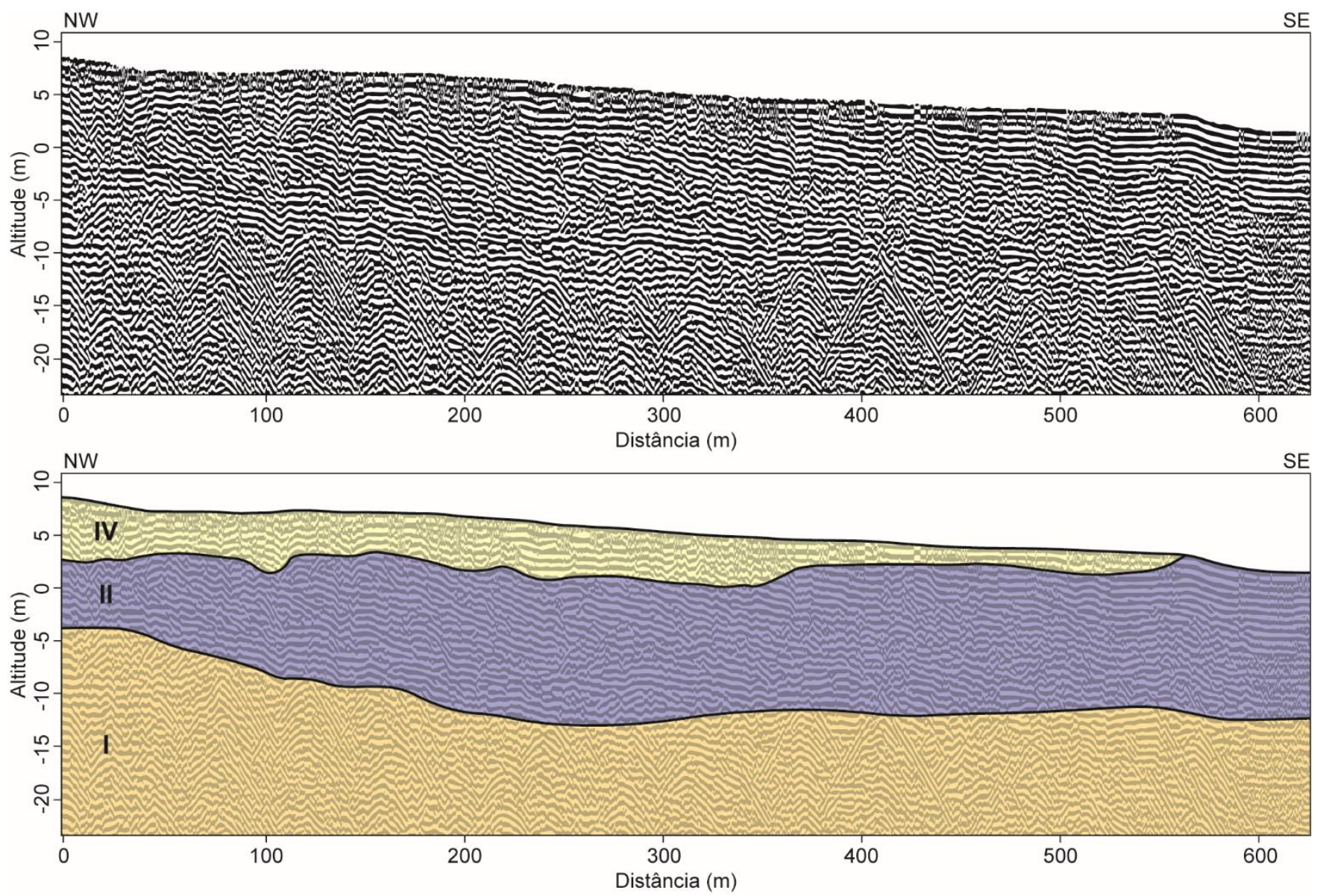

FIGURA 8. Imagem acima apresentando o radargrama processado do Balneário Campo Bom. Abaixo o registro estratigráfico interpretado com as respectivas unidades deposicionais e/ou ambientes: I - depósitos correspondentes ao substrato pleistocênico; II - depósitos correspondentes ao perfil praial (emerso e submerso); IV - depósitos eólicos.

\section{Discussão}

Quando se pensa em gestão costeira é necessária uma avaliação das mais diversas variáveis que compõem o sistema costeiro e um sistema de mediação dos conflitos de interesse das partes envolvidas. O sistema público vigente ampara o desenvolvimento dos instrumentos previstos para a gestão integrada. Contudo, se observa pouco apoio político-institucional, cujas possíveis causas podem-se citar: a falta de conhecimento e informação sobre o meio ambiente e gestão costeira; conflitos de interesse (conservação vs. ocupação); e, em perspectiva operacional, pela disponibilidade restrita de recursos para implementar as ações de GCI.

No Município de Jaguaruna foram observadas dificuldades de acesso a cursos de formação ou capacitação em gestão costeira, principalmente acesso a cursos voltados a gestores públicos. Nessa perspectiva, a Educação Ambiental, mesmo que ocorra de forma inexpressiva no Município, ainda é o principal meio de transmissão de informações sobre o meio ambiente.

Apesar do embargo, foi observado um aumento no número de moradias. Fato resultante de "grilagem" e invasões de áreas particulares, do descaso de grandes proprietários de terra (que continuavam a instalar infraestrutura urbanas para venda de lotes) ou da falta de ação do poder público municipal (que acabou encorajando o desrespeito ao embargo). Ao averiguar a preservação das APPs e APs, foi constatado que, apesar da legislação ambiental vigente e mesmo após a instauração do embargo, estas áreas de interesse ambiental estão sob influência e/ou impactadas pela ação antrópica. Tais fatos demonstram a incapacidade de implementar ações esperadas de controle e fiscalização no âmbito do Município de Jaguaruna.

Assim como Andrade e Scherer (2014), que aplicaram o Decálogo para uma avaliar a gestão costeira no Estado de Santa Catarina, neste trabalho também foi constatado que a existência de entraves administrativos e financeiros dificultam a implementação da gestão costeira no Município de Jaguaruna. Tais dificuldades também foram 
identificadas por Gruber et al. (2018): a existência de uma dissonância de discursos e capacidades operacionais em nível administrativo entre órgãos e instituições municipais, estaduais e federais; o que resulta em dificuldades na implementação da gestão costeira em âmbito local.

Essa dissonância é percebida pela interpretação do embargo, o qual é percebido: como um "grande entrave econômico" pelo Município de Jaguaruna; como um "problema complexo que deve ser gerido e resolvido pelo Município" pelas demais órgãos das esferas estadual e federal; e como uma "salvarguarda da legislação ambiental" pelo MPF, haja vista o crescente número de conflitos em APPs.

Ao definir as prioridades, os gestores devem ter conhecimento sobre a dinâmica ambiental local. Os dados obtidos com o Georadar demonstram que a área de estudo tem um padrão de empilhamento estratigráfico progradacional, setores com esse comportamento possuem, em termos de escala de centenas e milhares de anos (longo período), uma linha de costa regressiva (deslocamento no sentido continente - oceano); esse comportamento também foi observado por Oliveira, Barboza e Benavente (2016) no Balneário Campo Bom e por Leal et al. (2016) no Balneário Torneiro (também com a presença de paleocanais). A presença de paleocanais colmatados indica um grande aporte sedimentar junto a essa região, oriundo da dinâmica costeira, caracterizando uma morfologia plana ao terreno.

A partir dessas informações pode-se concluir que a área de estudo não apresenta problemas de erosão de longo período. Essa condição favorece o uso e ocupação da terra, pois setores com essas características, mantendo a atual dinâmica costeira, são estáveis.

Não obstante, ao comparar fotografias aéreas entre anos de 1938 e 2012 em ambiente de SIG, Gruber et al. (2017c) observaram uma variação da linha de costa no sentido oceano - continente (linha de costa transgressiva). Como ainda não é possível explicar as causas e a relevância dessa divergência entre as tendências de comportamento de longo período/geológico (linha de costa regressiva) e de curto período/histórico (linha de costa transgressiva), cabe à gestão pública monitorar a evolução da linha de costa e promover em seu zoneamento urbano usos baseados nas dinâmicas ambientais; evitando, por exemplo, a preponderância da especulação imobiliária.

Gruber et al. (2017c) também observaram uma diminuição na ocorrência de dunas móveis e um aumento da fixação de vegetação entre os anos de 1938 e 2012 (FIGURA 9). Essa alteração na paisagem transformou os lençóis de areia nas feições mais comuns na paisagem em área preservada ao Sudoeste do Balneário Esplanada; condição que provavelmente se repetirá na área de estudo, haja vista a identificação de lençóis de areia em áreas não ocupadas e em meio a mancha urbana (FIGURA 2).

Essa alteração nas condições da paisagem subjaz à ocupação urbana, mas também não tem sido desconsiderada nos momentos de tomada de decisão. Os lençóis de areias transgressivos são utilizados como substrato para o assentamento urbano, o que tem aumentado a taxa de impermeabilização da superfície em um ambiente de recarga de aquífero. Além disso, a canalização do escoamento superficial é direcionada ao mar seguindo a declividade das vias públicas, o que normalmente termina por desconfigurar a continuidade das dunas frontais e provocar erosão na face de praia. Ainda cabe ressaltar que, em um ambiente com lençol freático raso e solo poroso (com frequente uso de água subterrânea), a instalação e manutenção da infraestrutura de esgotamento sanitário (comumente fossa séptica ou sumidouro, segundo dados do censo populacional de 2010) carecem de fiscalização. Em condição de recursos limitados, desconsiderar limitações de natureza ambiental pode resultar em adequações vultuosas.

\section{Conclusões}

As informações obtidas por meio do Decálogo permitiram constatar que, em relação ao uso equilibrado e sustentável da zona costeira, a área de estudo apresenta gestão ineficiente, apesar da existência de um arcabouço sobre legislação ambiental sólida. A falta de recursos humanos, técnicos, tecnológicos e financeiros é um dos maiores entraves à gestão costeira no Município de Jaguaruna. Não obstante, a morosidade nos momentos de tomada de decisão por parte do poder público municipal colaborou para o aumento dos conflitos, mesmo após o embargo.

Além disso, a dinâmica e as limitações de natureza ambiental são desconsideradas no momento da tomada de decisão. Fato que tende a influenciar negativamente o planejamento de longo prazo, pois não são computados os efeitos cumulativos ou contínuos oriundos de ações ambientalmente impróprias. 
Revista Brasileira de Geomorfologia, v. 22, n.4, 2021
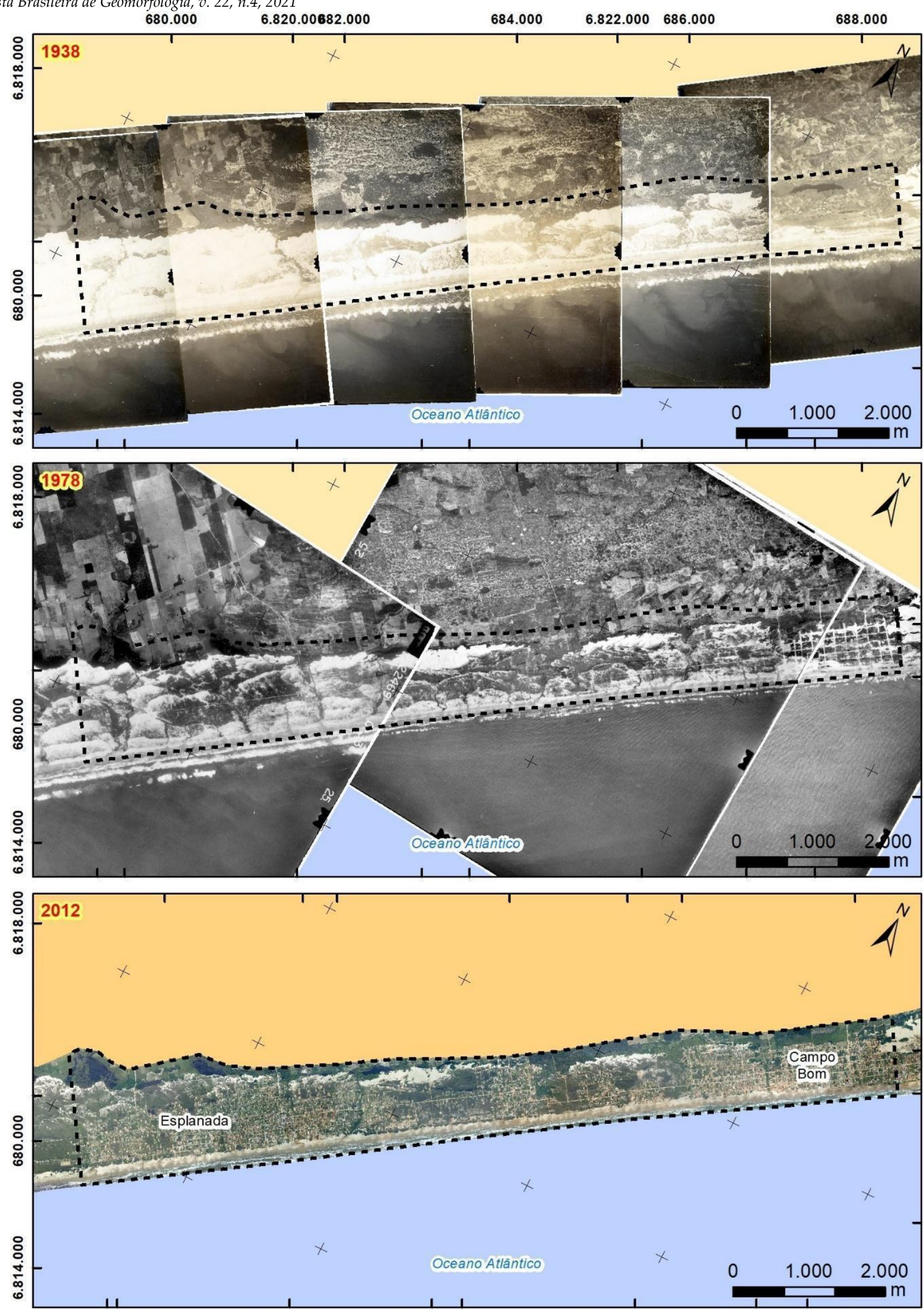

FIGURA 9. Uso da terra na área de estudo nos anos 1938, 1978 e 2012. Fonte: Gruber et al., (2017c). 
A aplicação do Georadar permitiu identificar através do padrão de empilhamento estratigráfico que na região dos balneários Esplanada e Campo Bom não existem tendências erosivas de longo período. Esse comportamento é divergente daquele encontrado por Gruber et al. (2017c) após análise da linha de costa em fotografias aéreas dos anos de 1938, 1978 e 2012: tendência transgressiva. Mesmo sem saber as causas dessa divergência, esse fato evidencia a importância do emprego de técnicas que abrangem escalas de tempo distintas (nesse caso, geológica e histórica).

Conclui-se que o sucesso da gestão costeira no Município de Jaguaruna, e consequentemente na área de estudo, requer a redefinição das prioridades políticas no Município, a iniciativa por parte dos gestores municipais pela construção de consensos com órgãos públicos estaduais e federais. Nessa perspectiva, se faz necessária a presença constante de interlocutores que tenham como meta: (i) promover o diálogo político e técnico convergente, e (ii) traduzir as idiossincrasias institucionais entre os distintos órgãos das esferas de poder.

Contribuições dos Autores: Concepção, Becker, Barboza e Martins; metodologia, Becker, Barboza e Martins; análise formal, Becker e Martins; pesquisa, Becker e Martins; preparação de dados, Becker, Barboza e Martins; escrita do artigo, Becker, Barboza e Martins; revisão, Becker e Barboza. Todos os autores leram e concordaram com a versão publicada do manuscrito.

Financiamento: Esta pesquisa não recebeu nenhum financiamento externo.

Agradecimentos: Cintia Becker e Eduardo Barboza agradecem ao CNPq pelas suas bolsas de Mestrado e de Produtividade em Pesquisa. Os autores agradecem ao projeto IAP-000097/IGEO/UFRGS - PLANO DE MANEJO DE DUNAS DO MUNICÍPIO DE JAGUARUNA - SC, pelo apoio nas atividades de campo.

Conflito de Interesse: Os autores declaram não haver conflito de interesse.

\section{Referências}

1. ABREU, V. S.; NEAL, J.; VAIL, P. R. Integration of Sequence Stratigraphy concepts. In: ABREU, V. S.; NEAL, J.; BOHACS, K. M.; KALBAS, J. L. (Eds.). Sequence Stratigraphy of siliciclastic systems - The ExxonMobil Methodology: atlas of exercises, 2010. p. 209-224.

2. ALVARES, C. A.; STAPE, J. L.; SENTELHAS, P. C.; GONÇALVES, J. L. M.; SPAROVEK, G. Köppen's climate classifi cation map for Brazil. Meteorologische Zeitschrift, v. 22, p. 711-728, 2013. DOI: 10.1127/09412948/2013/0507

3. ANA - Agência Nacional de Águas. Lista de Termos para o Thesaurus de Recursos Hídricos na Agência Nacional de Águas, 2014, 43p. Disponível em: $<$ https://arquivos.ana.gov.br/imprensa/noticias/20150406034300_Portaria_149-2015.pdf >.

4. ANGULO, R. J.; GIANNINI, P. C. F.; SUGUIO, K.; PESSENDA, L. C. R. The relative sea-level changes in the last 5500 years southern Brazil (Laguna-Imbituba region, Santa Catarina State) based on vermetid ${ }^{14} \mathrm{C}$ ages. Marine Geology, v. 159, 327-339, 1999. DOI: 10.1016/S0025-3227(98)00204-7

5. ANDRADE, J.; SCHERER, M. E. G. Decálogo da gestão costeira para Santa Catarina: avaliando a estrutura estadual para desenvolvimento do Programa Estadual de Gerenciamento Costeiro. Desenvolvimento e Meio Ambiente, v. 29, p. 139-154, 2014. DOI: 10.5380/dma.v29i0.31405

6. ARAÚJO, C. E. S.; FRANCO, D.; MELO, E.; PIMENTA, F. Wave regime characteristics of southern Brazilian Coast. In: In: COLOMBO (Ed.), Proceedings of the Sixty International Conference on Coastal and Port Engineering in Developing Countries, COPEDEC VI, Sri Lanka, vol. 2003 Paper n. 097. 2003. p. 1-15 (CDROM).

7. ASMUS, M. L.; KITZMANN, D. I. S; LAYDNER, C.; TAGLIANI, C. R. A. Gestão Costeira no Brasil: Instrumentos, Fragilidades e Potencialidades. 2006. Disponível em: $<$ http://repositorio.furg.br/handle/1/2053>.

8. BARBOZA, E. G.; ROSA, M. L. C. C.; HESP, P. A.; DILLENBURG, S. R.; TOMAZELLI, L. J.; AYUP-ZOUAIN, R. N. Evolution of the Holocene coastal barrier of Pelotas Basin (southern Brazil) - a new approach with GPR data. Journal of Coastal Research, v. SI 64, p. 646-650, 2011.

9. BARBOZA, E. G.; ROSA, M. L. C. C.; DILLENBURG, S. R.; TOMAZELLI, L. J. Preservation potential of foredunes in the stratigraphic record. Journal of Coastal Research, SI 65, v. 2, p. 1265-1270, 2013. DOI: $10.2112 /$ SI65-214.1 
10. BARBOZA, E. G.; ROSA, M. L. C. C.; DILlENBURG, S. R.; BIANCINI DA SILVA, A.; TOMAZELLI, L. J. Stratigraphic analysis applied on the recognition of the interface between marine and fluvial depositional systems. Journal of Coastal Research, v. SI 70, p. 205-210, 2014. DOI:10.2112/SI70-116.1

11. BARBOZA, E. G.; ROSA, M. L. C. C.; DILLENBURG, S. R.; WATANABE, D. S. Z.; ESTEVES, T.; MARTINS, E. M.; GRUBER, N. L. S. Diachronic Condition Between Maximum Transgressive and Maximum Eustatic SeaLevel in Holocene: Subsidies for Coastal Management. Journal of Coastal Research, v. SI 85, p. 1-5, 2018. DOI: 10.2112/SI85-085.1

12. BARBOZA, E. G.; DILlENBURG, S. R.; RITTER, M. N.; ANGULO, R. J.; BIANCINI DA SILVA, A.; ROSA, M. L. C. C.; CARON, F.; SOUZA, M. C. Holocene Sea-Level Changes in Southern Brazil Based on High-Resolution Radar Stratigraphy. Geosciences (Switzerland), v. 11, n. 8, 326, 2021a. DOI: 10.3390/geosciences11080326

13. BARBOZA, E. G.; DILlENBURG, S. R.; LOPES, R. P.; ROSA, M. L. C. C.; CARON, F.; ABREU, V. S.; MANZOLLI, R. P.; NUNES, J. C. R.; WESCHENFELDER, J.; TOMAZELLI, L. J. Geomorphological and Stratigraphic Evolution of a Fluvial Incision in the Coastal Plain and Inner Continental Shelf in Southern Brazil. Marine Geology, v. 437, 106514, 2021b. DOI: 10.1016/j.margeo.2021.106514

14. BARRAGÁN MUÑOZ, J. M. Las áreas litorales de España. Del análisis geográfico a la gestión integrada. Barcelona: Editorial Ariel S. A., 214p, 2004.

15. BARRAGÁN MUÑZ, J. M. Manejo Costero Integrado y Política Pública en Iberoamérica: Un diagnóstico. Necesidad de Cambio. Red IBERMAR (CYTED), Cádiz, Espanha. 380p., 2010.

16. BARRAGÁN MUÑOZ, J. M. Manejo Costero Integrado en Iberoamérica: Diagnóstico y propuestas para una nueva política pública. Red IBERMAR (CYTED), Cádiz, 152p, 2012.

17. BIANCINI DA SILVA, A.; BARBOZA, E. G.; ROSA, M. L. C. C.; DILLENBURG, S. R. Meandering fluvial system influencing the evolution of a Holocene regressive barrier in southern Brazil. Journal of Coastal Research, v. SI 70, p. 205-210. 2014. DOI: 10.2112/SI70-035.1

18. BITENCOURT, V. J. B.; DILLENBURG, S. R.; BARBOZA E. G.; ROSA, M. L. C. C.; MANZOLLI, R. P. Padrões de Empilhamento Estratigráfico e seus Reflexos na Morfologia da Barreira Costeira Holocênica no Litoral Médio do Rio Grande do Sul. Revista Brasileira de Geomorfologia, v. 21, n. 2, p. 140-165, 2020. DOI: 10.20502/rbg.v21i3.1789

19. CAMILO, R. F. Projeto Golfinho já formou mais de 800 crianças nesta temporada. Jaguaruna foi contemplada. Portal Jaguaruna. Disponível em: <http://www.portaljaguaruna.com/noticias/plantaoportal/projeto-golfinho-ja-formou-mais-de-800-criancas-nesta-temporada-jaguaruna-foi-contemplada>.

20. CASSETI, V. Ambiente e Apropriação do Relevo. São Paulo: Contexto, 2a ed. 147p, 1995.

21. CONAMA - Conselho Nacional do Meio Ambiente. Resolução no 261 de 30 de junho de 1999. Aprova parâmetros básicos para análise dos estágios sucessivos de vegetação de restinga para o Estado de Santa Catarina. Disponível em: <https://www.ibama.gov.br/component/legislacao/?view=legislacao\&legislacao=103595>.

22. DAVIS, J. L.; ANNAN, A. P. Ground-penetrating radar for high-resolution mapping of soil and rock stratigraphy. Geophysical Prospecting, v. 37, p. 531-551, 1989. DOI: 10.1111/j.1365-2478.1989.tb02221.x

23. DILlENBURG, S. R.; BARBOZA, E. G. The Strike-Fed Sandy Coast of Southern Brazil. In: MARTINI, I. P.; WANLESS, H. R. (Eds.). Sedimentary Coastal Zones from High to Low Latitudes: Similarities and Differences. Geological Society of London, Special Publications v. 388, 2014. p. 333-352. DOI: 10.1144/SP388.16

24. DILlENBURG, S. R.; BARBOZA, E. G.; HESP, P. A.; ROSA, M. L. C. C. Ground Penetrating Radar (GPR) and Standard Penetration Test (SPT) records of a regressive barrier in southern Brazil. Journal of Coastal Research, v. SI 64, p. 651-655, 2011.

25. DIllenburG, S. R.; BARBOZA, E. G.; ROSA, M. L. C. C.; CARON F.; SAWAKUCHI, A. O. The complex prograded Cassino barrier in southern Brazil: Geological and morphological evolution and records of climatic, oceanographic and sea-level changes in the last 7-6 ka. Marine Geology, 390, p. 106-119, 2017. DOI: 10.1016/j.margeo.2017.06.007

26. EDUCAÇÃO AMBIENTAL. Portal de Educação Ambiental/ SC. Disponível em: $<$ http://educacaoambiental.sds.sc.gov.br/index.php/quem-somos>.

27. FATMA - Fundação do Meio Ambiente. Delimitação e planejamento de demarcação do Parque Estadual da Serra do Tabuleiro. Diagnóstico Socioeconômico e Ambiental. Relatório Final 03FAT0206R01. Projeto de Proteção da Mata Atlântica em Santa Catarina (PPMA/SC) / Cooperação Bilateral Brasil - Alemanha. Curitiba, 
<http://www.fatma.sc.gov.br/pautas/rimas_site/serra_tabuleiro/relatorio_socioambiental.pdf $>$.

28. FERNANDEZ, G. B.; ROCHA, T. B.; BARBOZA, E. G.; DILLENBURG, S. R.; ROSA, M. L. C. C.; ANGULO, R. J.; SOUZA, M. C.; OLIVEIRA, L. H. S.; DOMINGUEZ, J. M. L. Natural landscapes along Brazilian coastline. In SALGADO, A. A. R.; SANTOS, L. J. C.; PAISANI, J. C. (Org.). The Physical Geography of Brazil Environment, Vegetation and Landscape. Springer, Cham, 2019. p. 199-218. DOI: 10.1007/978-3-030-043339_10

29. FERREIRA, W. L. S.; ASMUS, M. L. "PERMACOAST": Aproximação Conceitual e Metodológica Entre Gestão Costeira Integrada e Permacultura. Revista Costas, v. 1, n. 1, p. 23-40, 2019. DOI: 10.26359/costas.0102

30. GERCO/SC - Programa Estadual De Gerenciamento Costeiro De Santa Catarina. Implantação do Plano Estadual de Gerenciamento Costeiro - Diagnóstico Sócio Ambiental dos Setores do Litoral de Santa Catarina. Secretaria do Planejamento do Estado de Santa Catarina. p. 416, 2010.

31. GIANNINI, P. C. F. Sistemas deposicionais no Quaternário costeiro entre Jaguaruna e Imbituba, SC. Tese (Doutorado em Geociências). Instituto de Geociências, Universidade de São Paulo, São Paulo, 1993. 2 volumes. 2 mapas. 439 f. DOI: 10.11606/T.44.1993.tde-11032013-133424

32. GIANNINI, P. C. F. Complexo lagunar centro-sul catarinense: valioso patrimônio sedimentológico, arqueológico e histórico. In: SCHOBBENHAUS, C.; CAMPOS, D. A.; QUEIROZ, E. T.; WINGE, M.; BERBERTBORN, M. L. C. (Eds.). Sítios geológicos e paleontológicos do Brasil. DNPM/CPRM - Comissão Brasileira de Sítios Geológicos e Paleobiológicos (SIGEP): Brasília/DF, 2002. 554p.

33. GIANNINI, P. C. F.; SANTOS, E.R. Padrões de variação espacial e temporal na morfologia de dunas de orla costeira no centro-sul catarinense. Boletim Paranaense de Geociências, v. 42, p. 73-96, 1994.

34. GRUBER, N. L. S.; STROHAECKER, T. M.; PORTZ, L. C.; ROCKETT, G. C.; WATANABE, T. P.; BITENCOURT, V. J. B.; MARTINS, E. M. Projeto diagnóstico e plano de manejo das dunas frontais do município Jaguaruna: Arcabouço teórico-conceitual. 2a ${ }^{\underline{a}}$ Ed. V. 1. Porto Alegre: UFRGS. 86 p, 2017a Disponível em: < www.bibliotecadigital.ufrgs.br/da.php?nrb=001065735\&loc=2018\&l=f03de8786f93a4b4 >. Acesso em: 22 jan. 2021.

35. GRUBER, N. L. S.; BARBOZA, E. G.; MARTINS, E. M.; PRESTES, L. D.; CRISTIANO, S. C. Diagnóstico e Plano de Manejo das Dunas Frontais do Município de Jaguaruna: Fundamentação metodológica. V. 1. Porto Alegre: UFRGS. 107 p, 2017b.

36. GRUBER, N. L. S.; PORTZ, L. C.; CRISTIANO, S. C.; OLIVEIRA, R. M.; OLIVEIRA, J. F.; ROCKETT, G. C.; MIRANDA, I. M.; MANZOLLI, R. P.; MARTINS, E. M. Diagnóstico e Plano de Manejo das Dunas Frontais do Município de Jaguaruna: ORLA Marítima: morfodinâmica e aspectos ecológicos do sistema eólico-praial. 2 $2^{\mathrm{a}}$ Ed. V. 2. Porto Alegre: UFRGS. 85 p, 2017c. Disponível em: < www.bibliotecadigital.ufrgs.br/da.php?nrb=001065735\&loc=2018\&arq=2\&l=ff43bb3edead8309 >. Acesso em: 22 jan. 2021.

37. GRUBER, N. L. S.; BARBOZA, E. G.; MARTINS, E. M.; BECKER, C.; PEIXOTO, J. S.; DADALT, R. C.; FRANCHINI, R. A. L.; CERCINÁ, M.; VILELLA, M. M. Plano de Diagnóstico e Plano de Manejo das Dunas Frontais do Município de Jaguaruna: ORLA Marítima: Bloco entre os balneários Campo Bom e Esplanada - Dunas Interiores. V. 6. Porto Alegre: UFRGS. 298 p, 2018.

38. HESP, P. A. Morphology, Dynamics and Internal Stratification of some established foredunes in southeast Australia. Sedimentary Geology, v. 55, p. 17-41, 1988. DOI: 10.1016/0037-0738(88)90088-7

39. HESP, P. A. Coastal Sand Dunes: form and function. CDVN Technical Bulletin, $\mathbf{n}^{\circ} \mathbf{4}$. Massey University, New Zealand, 28p, 2000.

40. HESP, P. A. Foredunes and blowouts: initiation, geomorphology and dynamics. Geomorphology, v. 48, p. 245268, 2002. DOI: 10.1016/S0169-555X(02)00184-8

41. HORN-FILHO, N. O.; FELIX, A.; VIEIRA, C. V.; BAPTISTA, E. M. C.; MALANDRIN, D. A., LEAL, R. A., MACHADO, V. C.; SILVA, M. Mapa geológico da planície costeira das folhas Lagoa de Garopaba do Sul (SH22-Z-XB-V-1) e Jaguaruna (SH-22-X-B-IV-2), Santa Catarina, Brasil. In: HORN FILHO, N.O. (Org.). Atlas geológico da planície costeira do estado de Santa Catarina em base ao estudo dos depósitos quaternários. Série mapas IBGE - Mapa $\mathbf{n}^{\circ}$ 9. Escala 1:100.000. Florianópolis: UFSC/CFH (Departamento de Geociências e Programa de Pós-Graduação em Geografia), CNPq. 2012. 
42. IBGE - Instituto Brasileiro de Geografia e Estatística. Atlas geográfico das zonas costeiras e oceânicas do Brasil. Rio de Janeiro. 2011. 176p. Disponível em: <https://biblioteca.ibge.gov.br/visualizacao/livros/liv55263.pdf>.

43. IDALÊNCIO, J. C.; PACHECO, F. Presidente do Legislativo Jaguarunense Recebeu Equipe da UFRGS Para Entrega de Plano de Manejo. Câmara Municipal de Jaguaruna, Jaguaruna, 07 de fevereiro de 2019. Disponível em: <https://www.camarajaguaruna.sc.gov.br/camara/conteudo/publicacoes/Noticias/1/2019/18>.

44. JAGUARUNA. Lei no 1413, de 2011. Cria o Instituto Municipal do Meio Ambiente de Jaguaruna, e dá outras providências. Disponível em: <https://leismunicipais.com.br/a/sc/j/jaguaruna/lei-ordinaria/2011/142/1413/leiordinaria-n-1413-2011-cria-o-instituto-municipal-do-meio-ambiente-de-jaguaruna-e-da-outras-providencias $>$.

45. JAGUARUNA. Lei Complementar n⿳0 04, de 07 de janeiro de 2014. Dispõe sobre o Plano Diretor do Município de Jaguaruna e dá outras providências. Disponível em: <https://leismunicipais.com.br/plano-diretorjaguaruna-sc>.

46. KLEIN, R. M. Mapa fitogeográfico do estado de Santa Catarina. Flora Ilustrada Catarinense, parte V: Mapa fitogeográfico. Itajaí: Herbário "Barbosa Rodrigues”. 24p. 1978.

47. LEAL, R. A.; BARBOZA, E. G.; BITENCOURT, V. J. B.; SILVA, A. B.; MANZOLLI, R. P. Geological and stratigraphic characteristics of a Holocene regressive barrier in Southern Brazil: GIS and GPR applied for evolution analysis. Journal of Coastal Research, v. SI 75, p. 750-754, 2016. DOI: 10.2112/SI75-151.1

48. LEANDRO, C. G.; BARBOZA, E. G.; CARON, F.; JESUS, F. A. N. GPR trace analysis for coastal depositional environments of southern Brazil. Journal of Applied Geophysics, v. 162, p. 1-12, 2019. DOI: 10.1016/j.jappgeo.2019.01.002

49. MAPBIOMAS. Projeto MapBiomas - Coleção 4 da Série Anual de Mapas de Cobertura e Uso do Solo do Brasil cobrindo o período de 1985 - 2018. 2019. Disponível em: <http://mapbiomas.org/>.

50. MARTINHO, C. T. Morfodinâmica e sedimentologia de campos de dunas transgressivos da região de Jaguaruna - Imbituba, Santa Catarina. 108 f. São Paulo: Universidade de São Paulo, 2004. Dissertação (Mestrado em Geociências). Instituto de Geociências. Universidade de São Paulo, São Paulo, 2004. DOI: 10.11606/D.44.2004.tde-27082015-155817

51. MARTINS, E. M.; GRUBER, N. L. S.; BARBOZA, E. G.; CRISTIANO, S. C.; PRESTES, L. D.; MANZOLLI, R. P.; PORTZ, L. C.; ROCKETT, G. C.; OLIVEIRA, J. F.; OLIVEIRA, R. M.; FRANCHINI, R. A. L.; BITENCOURT, V. J. B.; WATANABE, T. P.; LEAL, R. A.; BRAGA, R. B.; FONTES, J. L. B.; WATANABE, D. S. Z.; VIANNA, N. Z.; FERREIRA, B. F.; FAGUNDES, M. R.; VILLELA, M. M.; ESTEVES, T.; AZARIAS, P. C. Subsídios para o planejamento estratégico costeiro do município de Jaguaruna, Santa Catarina. Desenvolv. Meio Ambiente, v. 44, 267-289, 2018. DOI: 10.5380/dma.v44i0.54885

52. MITCHUM Jr., R. M.; VAIL, P. R., SANGREE, J. B. Seismic Stratigraphy and Global Changes of Sea Level, Part 6: Stratigraphic Interpretation of Seismic Reflection Patterns in Depositional Sequences. In Payton C. E. (Ed.). Seismic Stratigraphy: Applications to Hydrocarbon Exploration. AAPG Memoir, 26, 1977. p. 117-133. DOI: 10.1306/M26490C8

53. MMA - Ministério do Meio Ambiente - Secretaria Executiva - Departamento de Gestão Estratégica. IV Plano de Ação Federal para a Zona Costeira. 2017/ 2019. 36p, 2017.

54. MMA - Ministério do Meio Ambiente - Instituto Chico Mendes - APA da Baleia Franca, Plano de Manejo. 2018. Disponível em: <http://www.icmbio.gov.br/portal/images/stories/plano-demanejo/plano_de_manejo_apa_da_baleia_franca.pdf $>$.

55. MUEHE. D. A Geomorfologia costeira e seu desdobramento para a geografia costeira e marinha. Revista Brasileira de Geografia, v 1, p. 29-59, 2018.

56. NEAL, A. Ground-penetrating radar and its use in sedimentology: principles, problems and progress. EarthScience Reviews, v. 66, n. 3-4, p. 261-330, 2004. DOI: 10.1016/j.earscirev.2004.01.004

57. NETTO, P. Campanha educativa chama a atenção para preservação dos recursos naturais. Portal Jaguaruna. 2019. Disponível em: <http://www.portaljaguaruna.com/noticias/saude/colunista-paiva-netto-campanhaeducativa-chama-a-atencao-para-a-preservacao-dos-recursos-naturais $>$.

58. OLIVEIRA, J. F.; BARBOZA, E. G.; BENAVENTE, J. Nearshore Dynamics and Holocene Evolution of the Coastal Barrier South of the Santa Marta Cape, Southern Brazil. Journal of Coast Research, v. SI, 75, p. 437441, 2016. DOI: 10.2112/SI75-088.1 
59. OLIVEIRA, J. F.; BARBOZA, E. G.; MARTINS, E. M., SCARELLI, F. M. Geomorphological and stratigraphic analysis applied to coastal management. Journal of South American Earth Sciences, v. 96, 102358, 2019. DOI: 10.1016/j.jsames.2019.102358

60. ORSELLI, L. Climatologia. In: Atlas de Santa Catarina. Santa Catarina, Gabinete do Planejamento e Coordenação Geral. 1986. p. 38-39.

61. RAMOS, M. G.; SERPA, P. N.; SANTOS, C. B. DOS; FARIAS, J. C. Manual de silvicultura: I - Cultivo e manejo de florestas plantadas. Florianópolis: Epagri Boletim Didático, 61, 55p, 2006.

62. ROSA, M. L. C. C.; BARBOZA, E. G.; DILLENBURG, S. R.; TOMAZELLI, L. J.; AYUP-ZOUAIN, R. N. The Rio Grande do Sul (southern Brazil) shoreline behavior during the Quaternary: A cyclostratigraphic analysis. Journal of Coastal Research, v. SI 64, p. 686-690. 2011.

63. ROSA, M. L. C. C.; BARBOZA, E. G.; ABREU, V. S.; TOMAZELLI, L. J.; DILLENBURG, S. R. High-Frequency Sequences in the Quaternary of Pelotas Basin (coastal plain): a record of degradational stacking as a function of longer-term base-level fall. Brazilian Journal of Geology, v. 47, n. 2. p. 183-207, 2017. DOI: 10.1590/23174889201720160138

64. SANTA CATARINA. Lei $\mathbf{n}^{\circ} \mathbf{1 3 . 5 5 3}$ de 16 de novembro de 2005. Institui o Plano Estadual de Gerenciamento Costeiro. Palácio Barriga Verde. Florianópolis, SC. Alterada pelas Leis: 14.465/08; 14.736/09. Disponível em: $<$ http://www.pmf.sc.gov.br/arquivos/arquivos/pdf/20_12_2013_14.42.03.a2e22f23e586618411dac93b87852584. pdf $>$.

65. SIEGLE, E.; ASP, N. E. Wave refraction and longshore transport patterns along the Southern Santa Catarina Coast. Brazilian Journal of Oceanography, v. 55, n. 2, p. 109-120, 2007. DOI: 10.1590/S1679-87592007000200004

66. SPG - Secretaria de Estado do Planejamento de Santa Catarina. Implantação do Plano Estadual de Gerenciamento Costeiro - Fase 1: Zoneamento Ecológico Econômico Costeiro Setor Litoral Centro-Sul. Florianópolis/Santa: SPG. 160p, 2010a. Disponível em: <www.spg.sc.gov.br/acoes/20-gerco>.

67. SPG - Secretaria de Estado do Planejamento de Santa Catarina. Implantação do Plano Estadual de Gerenciamento Costeiro: Diagnóstico Socioambiental - Setor Litoral Centro-Sul, SC. 2010b. 493 p. Disponível em: <www.spg.sc.gov.br/acoes/20-gerco $>$.

68. SPG - Secretaria de Estado do Planejamento de Santa Catarina. Revisão do Plano de Gestão da Zona Costeira: Setor 04 - Centro-Sul. 2013. 41 p. Disponível em: <www.spg.sc.gov.br/acoes/20-gerco >.

69. TRF4 - Tribunal Regional Federal da $4^{a}$ Região. Plano de Manejo da APA da Baleia Franca (SC) é suspenso por TRF4. 31 de julho de 2019.2 Disponível em: $<$ https://www.trf4.jus.br/trf4/controlador.php?acao=noticia_visualizar\&id_noticia=14647>.

70. VILLWOCK, J. A.; TOMAZELLI, L. J. Geologia Costeira do Rio Grande do Sul. Notas Técnicas, v. 8, 45p, 1995.

Esta obra está licenciada com uma Licença Creative Commons Atribuição 4.0 Internacional (http://creativecommons.org/licenses/by/4.0/) - CC BY. Esta licença permite que outros distribuam, remixem, adaptem e criem a partir do seu trabalho, mesmo para fins comerciais, desde que lhe atribuam o devido crédito pela criação original. 